STD-AR-07-01 (rev.1)

\title{
Supervisory Control Strategy Development
}

Cooperative Agreement DE-FC07-05ID14690

\author{
Task 4
}

Final Report

Rev. 1

February 2007

Westinghouse Electric Company LLC 


\section{LEGAL NOTICE}

This report was prepared by Westinghouse Electric Company LLC. Neither Westinghouse Electric Company LLC, nor any person acting on its behalf:

A. Makes any warranty or representation, express or implied including the warranties of fitness for a particular purpose or merchantability, with respect to the accuracy, completeness, or usefulness of the information contained in this report, or that the use of any information, apparatus, method, or process disclosed in this report may not infringe privately owned rights; or

B. Assumes any liabilities with respect to the use of, or for damages resulting from the use of, any information, apparatus, method, or process disclosed in this report. 
STD-AR-07-01

\title{
Supervisory Control Strategy Development
}

Cooperative Agreement DE-FC07-05ID14690

Task 4

Final Report

\author{
Revision 1 \\ February 2007 \\ Principal Investigator \\ Bojan Petrovic \\ Report Principal Author \\ Gary D. Storrick
}

Westinghouse Electric Company LLC 
(THIS PAGE INTENTIONALLY LEFT BLANK) 


\section{TABLE OF CONTENTS}

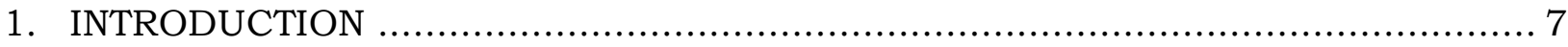

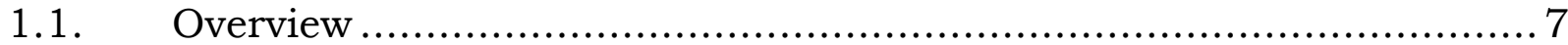

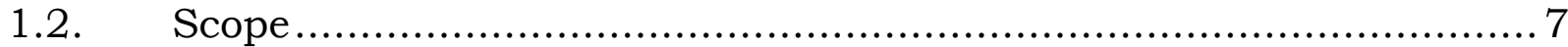

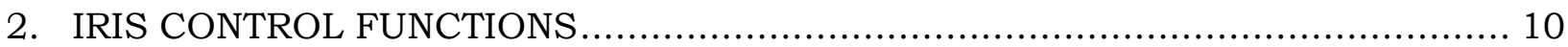

2.1. Control Concepts ........................................................... 10

2.2. Maneuvering Requirements ............................................. 11

2.3. Automated Sequences ..................................................... 13

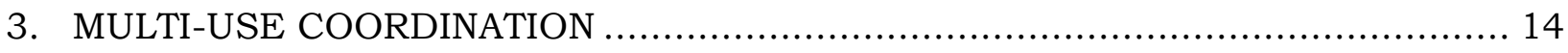

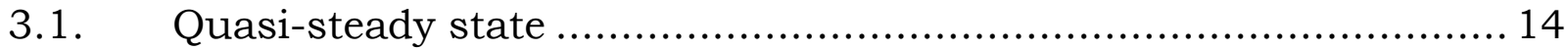

3.2. Daily fluctuations............................................................... 14

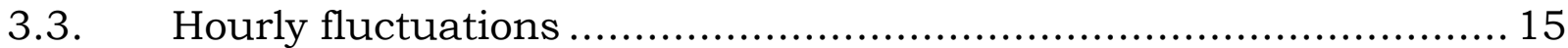

3.4. Minute-by-minute fluctuations............................................... 15

3.5. Reactor control system implications …................................. 15

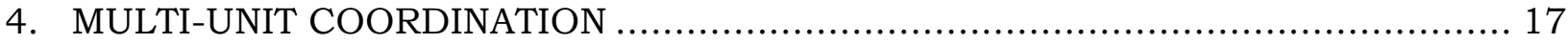

5. FUNCTIONAL REQUIREMENTS: PLANT MANEUVERING CAPABILITY ................ 22

5.1. Normal events ............................................................. 23

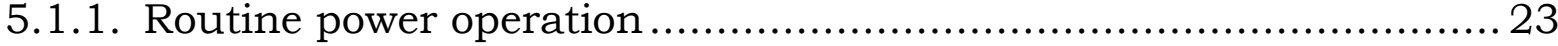

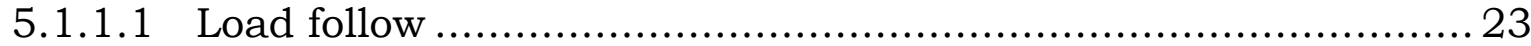

5.1.1.2 Dispatched load changes ........................................... 25

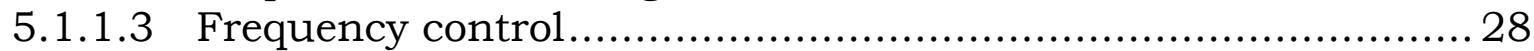

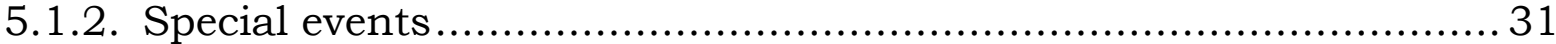

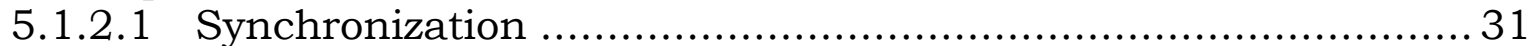

5.1.2.2 Short-term load increase ............................................ 33

5.1.2.3 Short-term load decrease .......................................... 35

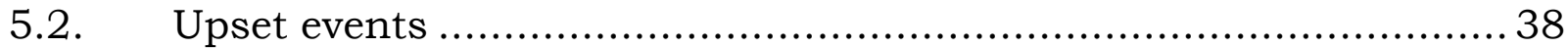

5.2.1. External electrical disturbances ...................................... 38

5.2.1.1 Grid islanding - increase ............................................ 38

5.2.1.2 Grid islanding - decrease ........................................ 40

5.2.1.3 Step load reduction to house load .................................... 42

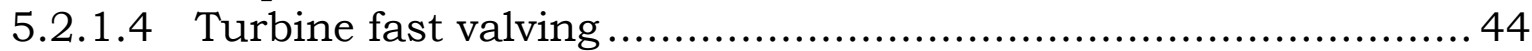


5.2.2. Reactor, turbine, and generator trips ..................................... 46

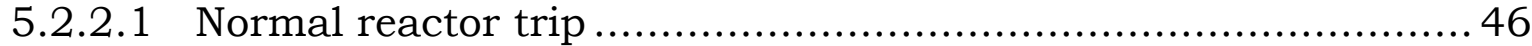

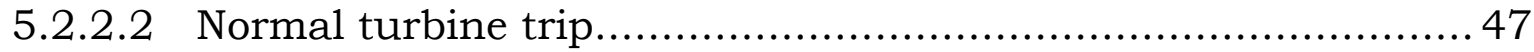

5.2.2.3 Normal generator trip ..................................................... 49

5.2.3. Loss of major plant components .......................................... 50

5.2.3.1 Loss of a running main reactor coolant pump ........................50 50

5.2.3.2 Loss of a running main feedwater pump ............................. 52

5.2.3.3 Loss of a running condensate pump ................................. 54

5.2.3.4 Inadvertent feedwater valve closure ....................................56 56

5.2.3.5 Loss of a feedwater heater............................................... 57

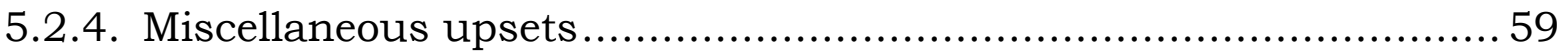

5.2.4.1 Unintended Control Rod Drop........................................... 59

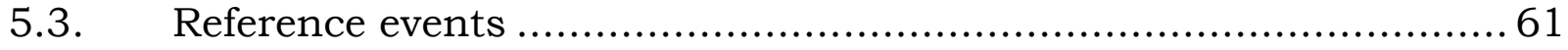

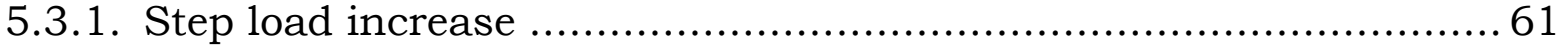

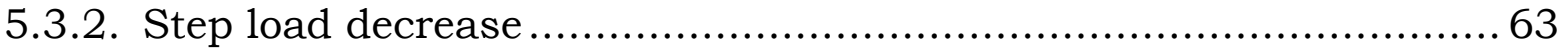

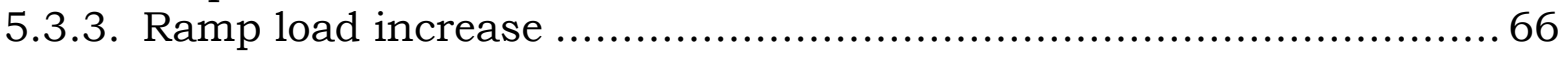

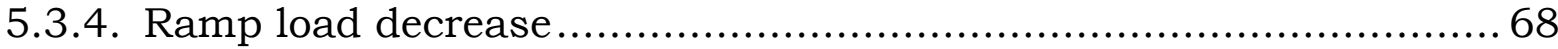

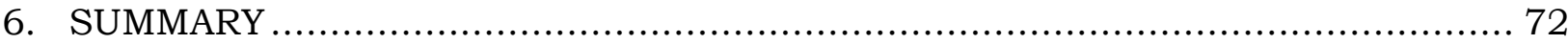

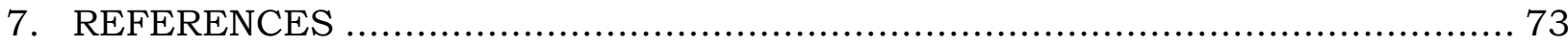




\section{INTRODUCTION}

\subsection{OVERVIEW}

Task four of the collaborative effort between ORNL, Brazil, and Westinghouse for the International Nuclear Energy Research Initiative entitled "Development of Advanced Instrumentation and Control for an Integrated Primary System Reactor" focused on the design of the hierarchical supervisory control for multiple-module units. The state of the IRIS plant design - specifically, the lack of a detailed secondary system design - made developing a detailed hierarchical control difficult at this time. However, other simultaneous and ongoing efforts have contributed to providing the needed information.

This report summarizes the results achieved under Task four. Section 1.2 describes the scope of this effort. Section 2 discusses the IRIS control functions. Next, it briefly reviews the current control concepts, and then follows this by reviewing the maneuvering requirements for the IRIS plant. It closes by noting the benefits that automated sequences have in reducing operator workload. Section 3 examines reactor loading in the frequency domain to establish some guidelines for module operation, paying particular attention to strategies for using process steam for desalination and/or district heating. The final subsection discusses the implications for reactor control, and argues that using the envisioned percentage (up to $10 \%$ ) of the NSSS thermal output for these purposes should not significantly affect the NSSS control strategies. Section 4 uses some very general economic assumptions to suggest how one should approach multi-module operation. It concludes that the well-known algorithms used for economic dispatching could be used to help manage a multi-unit IRIS site. Section 5 summarizes our conclusions.

\subsection{SCOPE}

The INERI contract scope of work task description for task 4, "supervisory hierarchical control design," is as follows:

1. "Task Description

"The IRIS control system architecture is being designed by the Instrumentation and Control Department of the Nuclear Automation Business Segment of Westinghouse. The architecture has been developed for a single unit plant having only electricity as its output. While this is consistent with one of the possible applications of the IPSRs $^{1}$

1 IPSR=Integrated Primary Systems Reactor 
technology and is consistent with the mission of other LWR designs, it fails to account for other IPSR applications that have been envisioned. Multiple units per site and cogeneration are part of the envisioned applications for IPSRs. Multiple unit operation must be optimized to successfully compete for deployment in countries where large electricity generation is required and can be supported, while small single unit size is attractive for countries with limited grid infrastructure. Co-generation applications are of interest to both developed and developing countries.

"An optimization of the plant operation for these different applications will not impact the overall low level control schemes, but will require the design of an appropriate supervisory hierarchical control, possibly capable of reconfiguring the balance of plant for different applications to provide a high level plant operation control. The main purpose of a supervisory control is to regulate the operation of the plant under different conditions and to reduce the operating staffing requirements.

"While the single unit supervisory control design will also be addressed, the main objective of this program is to develop an approach for different applications, either in a multi-unit park or for dual purpose plants."

The following section taken from the original proposal (Ref. 1) provides additional insight into the original intent of this task:

\section{2. "Supervisory Control Strategy Development}

"Westinghouse has previously developed a supervisory control strategy for the management of a single IRIS module during any operating range between hot zero power and hot full power. This supervisory control approach is IRIS specific (in particular it accounts for the transition modes between low and high power feedwater system control) but it is still based on Westinghouse technology, and in particular the most recent digital control system architectures. In this task, Westinghouse will address specific modes of operation envisioned for the IRIS reactor, including the control of multiple modules and the possibility of coupling the plant with desalination, district heating, and industrial steam cogeneration modules. In addition, more advanced solutions will be explored, for example the possibility of switching between power production and desalination for a unit with a reconfigurable balance of plant. This task will address all the 
necessary engineering and design issues that are required to properly characterize these modes of operation, but the focus will be on the design of the hierarchical supervisory control. ORNL will implement the developed simulation models and supervisory control module onto its I\&C test bed as a combined system demonstration." 


\section{IRIS CONTROL FUNCTIONS}

The vision for IRIS is for more than just a single-unit electric power generating station: it includes (1) an expectation for multiple units on one site, and (2) the possibility of coupling the plant with desalination, district heating, and industrial steam co-generation modules. There are numerous detailed issues involved that we cannot resolve without having more specific information, such as the number of units, the specific functions (electric, desalination, district heating, etc.) available on each, and the economic information needed to support specific control decisions; however, we can simplify the problem at this time by recognizing that the IRIS Nuclear Steam Supply System (NSSS) is simply that: a steam supply. In anthropomorphic language, IRIS does not care from where it gets its feedwater or for what we choose to use its steam: all IRIS knows is feedwater and steam flows and thermodynamic conditions. The IRIS design and the laws of thermodynamics constrain the acceptable steady-state feedwater and steam conditions in ways already established by other studies. As long as we design the secondary to supply feedwater and accept steam with flows and properties compatible with those constraints, IRIS will function properly as an NSSS. Let us look at the effects this has on (1) multi-unit coordination and (2) multi-use control for a single unit.

\subsection{CONTROL CONCEPTS}

Our earlier work (Ref. 2) proposed a conceptual design for controlling a single IRIS unit configured for electric power generation. In that report, we concentrated on the following control loops:

1. Supervisory control

2. Control rods

a. Reactor power control during startup

b. Primary loop temperature control at power

3. Pressurizer control

4. Steam generator control (i.e., determining feedwater flow)

5. Turbine control

6. Turbine bypass (a.k.a. steam dump) control

Although one cannot generally say "what controls what" in multi-input, multioutput systems, one can say where the control systems apply integral terms associated with particular errors. In Appendix A to Reference 2, Thomas Wilson and Richard Wood recommended pairing "the reactor average temperature with reactor power, core thermal power demand with total feedwater flow and steam pressure with steam flow." We concurred with these recommendations for normal power operation, and developed a conceptual control approach 
accordingly. We also considered startup operation, and proposed the following associations:

\begin{tabular}{|c|c|c|c|c|c|}
\hline Variable & $\begin{array}{c}\text { Reactor } \\
\text { tripped }\end{array}$ & $\begin{array}{c}\text { Hot zero } \\
\text { power }\end{array}$ & $\begin{array}{c}\text { Turbine } \\
\text { startup }\end{array}$ & $\begin{array}{c}\text { Low } \\
\text { Power }\end{array}$ & $\begin{array}{c}\text { High } \\
\text { Power }\end{array}$ \\
\hline Control Rods & $\mathrm{N} / \mathrm{A}$ & $\mathrm{Q}_{\mathrm{n}}$ & $\mathrm{Q}_{\mathrm{n}}$ & $\mathrm{Q}_{\mathrm{n}}$ & $\begin{array}{c}\mathrm{T}_{\text {avg }} \\
\mathrm{Q}_{\mathrm{n}} \text { stabilized }\end{array}$ \\
\hline $\begin{array}{c}\text { Feedwater } \\
\text { flow }\end{array}$ & $\Delta \mathrm{P}_{\mathrm{sg}}$ & $\Delta \mathrm{P}_{\mathrm{sg}}$ & $\Delta \mathrm{P}_{\mathrm{sg}}$ & $\Delta \mathrm{P}_{\mathrm{sg}}$ & $\mathrm{Q}_{\text {ref }}$ \\
\hline $\begin{array}{c}\text { Steam flow to } \\
\text { turbine }\end{array}$ & $\mathrm{N} / \mathrm{A}$ & $\mathrm{N} / \mathrm{A}$ & $\mathrm{rpm}$ & $\mathrm{P}_{\mathrm{s}}$ & $\mathrm{P}_{\mathrm{s}}$ \\
\hline Steam dump & $\mathrm{P}_{\mathrm{s}}$ & $\mathrm{P}_{\mathrm{s}}$ & $\mathrm{P}_{\mathrm{s}}$ & Biased $\mathrm{P}_{\mathrm{s}}$ & Biased $\mathrm{P}_{\mathrm{s}}$ \\
\hline
\end{tabular}

Finally, we developed the framework for a unit supervisory control that would coordinate the reactor, feedwater and turbine control systems during normal startup, power operation, and shutdown. The supervisory control would have the following functions:

- Establish the plant power reference signal. The IRIS plant is an electric power generating station, and the natural choice is generator electric power. The power reference signal will be used to derive reference and/or feedforward signals for the other major control loops.

- Monitor plant conditions and determine/coordinate the appropriate operating modes for the major control systems.

Reference 2 outlined the basic control strategies and provided a conceptual design for single-unit operation limited to electric power generation. We included a number of recommendations for further study, one of which, "Add external interfaces for any proposed multi-unit coordination (e.g., remote dispatching)" has particular direct bearing on the current study.

\subsection{MANEUVERING REQUIREMENTS}

Our earlier report proposed the following maneuvering requirements for IRIS units configured for electrical power generation:

1. Normal transients
A. Startup Transients

i. Initial turbine loading 
B. Power change transients

i. Daily load follow

ii. Ramp load changes

iii. Step load changes

iv. Grid frequency control

C. Shutdown transients

D. Event-based transients

i. $\quad$ Startup $\leftrightarrow$ main feedwater mode switching

ii. Bypass $\leftrightarrow$ main feedwater valve

iii. One $\leftrightarrow$ two main feedwater pumps

2. Abnormal events
A. Approach to protection or operational limits
B. Reactor trip
C. Turbine trip
D. Generator trip
E. Switchyard breaker trip
F. Islanding
G. Turbine fast valving
H. Feedwater pump trip
I. Reactor coolant pump trip
J. Feedwater and condensate train functions

The report proposed requirements for each of these events, and we will refine these requirements in Section 5 of the present report. At this time, there are few modifications necessary, although there are still several open issues. The primary change is to move "step load changes" to a third high-level category, "reference transients." We had already established that step changes in electrical load were not realistic transients, but were useful for control system design and analysis. Detailed analyses conducted since 2004 showed that using the control system design proposed then and subjecting the plant to a true step change in electrical load (i.e., a change from one finite grid to another of different size) did not result in any significant change in reactor output; instead, the energy mismatch forced the finite grid to accept the power mismatch by altering frequency. The reason, of course, is that the conceptual design developed in 2004 did not have a frequency correction to the reference power demand. Most grids are predominantly (say, 70\%) motor loads. These motors usually drive loads whose power consumption increases with speed (roughly as a quadratic function of grid frequency). Excess power generation forces the motors to increase speed until the loads reach speeds that consume the excess power; while insufficient power causes the motors to slow down until the load requirements drop to match the available power.

One solution would be to add a frequency correction to the reference power demand. Although this might be acceptable if the unit operates on an isolated 
grid, the preferred approach would be to recognize this as an islanding event and treat it with its own control mode (as recommended in Ref. 2). Westinghouse adopted this approach on the Temelin units in the Czech Republic, and the system has worked successfully when needed.

Frequency change issues do not arise for step changes in unit demand signals if the unit remains connected to an infinite grid. Under these conditions, a step change in requested electrical power generation would lead to a rapid change in generation at a rate limited by plant components (e.g., feedwater valve stroke time) and by any rate limits in the control systems. Generated frequency would remain at or near the nominal grid frequency throughout the event.

Reference 2 left "open issues" for us to decide which of the abnormal events must be in the IRIS plant design bases. The bases almost certainly should include the first five, and probably fast valving and islanding as well. The need to survive a feedwater pump trip will depend on the final feedwater system design, as will the need to survive specific feedwater and condensate train upsets. We do not currently promise the ability to operate with reactor coolant pumps out of service, but providing the capability makes an attractive area for future study. Section 5.2 provides a preliminary list along with the associated functional requirements.

\subsection{AUTOMATED SEQUENCES}

The IRIS program considers allowing one operating crew to monitor multiple units. Task 5 addressing human factors should consider this issue in more detail; however, it is clear that automating certain sequences associated with plant startup and shutdown could reduce the burden on the operators. The Westinghouse Supervisory Sequential Controller Interface (SSCI) system (Ref. 3) is an on-line, workstation-based system designed for operating procedure and sequential control applications in both power plants and process control facilities. The primary goal of the system is to provide a graphical user interface that allows for either user paced or system paced movement through plant operating procedures and control sequences. SSCI has the capability of monitoring plant status and issuing commands to plant control systems. By utilizing such a system to automate primary- and secondary-side startup and shutdown sequences, the IRIS I\&C system could reduce operator workload compared to traditional non-automated systems. 


\section{MULTI-USE COORDI NATION}

Expanding the plant vision beyond electric power generation to include desalination and/or district heating capability expands the need for secondary side design input. Although we do not have this input today, we can still make some observations by looking at the load variations each would place on IRIS. Specifically, we will consider quasi-steady state, daily load changes, hourly fluctuations, and minute-by-minute fluctuations.

\subsection{QUASI-STEADY STATE}

The simplest changes are those that occur over weeks or months. IRIS will, of course, have long-term variations in operating capability due to fuel depletion, steam generator fouling, equipment wear, and the occasional refueling outage. There may be seasonal demand changes for electricity, desalinated water, and district heating. We do not see that any of these pose significant new operating concerns for IRIS.

\subsection{DAILY FLUCTUATIONS}

The IRIS core will be susceptible to xenon-induced power distribution oscillations in the same way that similar PWR cores are. These oscillations have a period of just over a day, so daily power changes tend to initiate and support sustained oscillations. The core design recognizes this, and core operating strategies address the concerns. The important issue for IRIS is to avoid asking for daily power variations beyond the core design bases. Historically, these bases addressed daily fluctuations in electric power demand: for most grids, the demand for electric power decrease at night and on weekends. Since most grids have no practical means of storing electricity ${ }^{2}$, electric generation must follow these daily load variations. One feature of the Westinghouse Remote Dispatch Interface System mentioned earlier is its ability to account for xenon distributions in determining plant load change capability.

District heating demand should have a daily component, but in this case one would expect greater demand at night. If so, swings in district heating demand might partially offset swings in electricity demand, although we expect the effect would be small in most areas. Desalination demand could behave differently: although the demand for fresh water might peak at the same time as the demand for electricity, very simple technology (a tank) allows us to store desalinated water for later use. This suggests doing more of the desalination during times of low electric demand (night $\&$ weekends) and less during times

2 Pumped storage is perhaps the only credible option and then only in favorable terrain. 
of high electric demand (weekdays) to help balance the load demand throughout the day. As a side note, if the differential cost curve is convex (most are, at least at high power), then balancing load throughout the day has direct economic benefits as well.

\subsection{HOURLY FLUCTUATIONS}

Neither electric demand, district heating demand, nor desalination demand should have pronounced hourly variations commensurate with the daily fluctuations, nor should the IRIS plant have resonant frequencies in this band as it does for faster and slower events. Small fluctuations in this frequency range generally do not contribute to significant component fatigue, and wear should be less than it is for faster events. Designing the secondary to allow offsetting electric power demand fluctuations with desalination has benefits in this frequency range as well.

\subsection{MINUTE-BY-MINUTE FLUCTUATIONS}

Plants that have automatic load dispatching see electric power demand changes on a minute-by-minute bases, and most plants see smaller and faster fluctuations due to local frequency control. Each of these is more pronounced on smaller, less stable grids. Unfortunately, the NSSS has numerous time constants that lie in the few seconds to few minutes range, and steam flow fluctuations in this range tend to drive significant oscillations. Tight control may not be possible, and may even be undesirable because of the wear on control actuators (notable the control rod drive mechanisms). Traditional Westinghouse strategy has been to widen control deadbands during automatic dispatching to allow larger swings while reducing actuator demands; Westinghouse's U.S. patent 4,707,324 provides a more sophisticated approach that adjusts both set point and deadband to account for the expected process variable response to load fluctuations.

To our knowledge, there is no a-priori reason to expect desalination or district heating to contribute toward these fluctuations, so addressing those lies outside the scope of this study.

\subsection{REACTOR CONTROL SYSTEM IMPLICATIONS}

Reference 4 outlines the available desalination options. The Reverse Osmosis (RO) process relies mostly on electricity but may use steam to preheat the seawater. Multi-Stage Flash Distillation (MFD) and Multi-Effect Distillation (MED) each use steam as the principal energy source to evaporate seawater. The authors note, "The production of desalinated water is energy intensive....The choice of the desalination technology determines the energy

required: electrical energy for reverse osmosis systems, relatively low quality thermal energy for distillation systems, and both electrical and thermal energy 
for hybrid systems such as pre-heat RO systems." Their economic analyses suggested that a reverse osmosis desalination unit could provide water at approximately half the cost of an MSF unit. Since a pure reverse osmosis option uses electricity without requiring process steam, the desalination unit is simply another electric customer. The reverse osmosis option considered in their table 1 would require less than 16 MWe to operate. The IRIS unit need have no special control provisions to support this option.

Reference 4 considered coupling an IRIS plant with a MSF distillation unit by using low-pressure turbine extraction steam as a heat source. The paper does not state the thermal requirements, but presumably the authors assumed less than 5 percent of the reactor thermal power output. Reference 5 considered two larger MED options, requiring 200 and $150 \mathrm{MWt}$ respectively, again using extraction steam as the heat source. Naturally, all valves and pumps in an MED or MFD interface will require controls, but there should be little impact on the reactor controls. To see this, consider the Westinghouse experience with district heating on the two Temelin units.

The Temelin units are $3000 \mathrm{MWt}$ units that can supply $340 \mathrm{MWt}$ of district heating to the town of Týn, Czech Republic. On a percentage basis, this is two to three times the percentage envisioned for IRIS in references 4 and 5 . The heat source was a mix of extraction steam from various low- and high-pressure turbine stages ${ }^{3}$. When supplying full district heating, electricity production decreased $5-6 \%$. The effect on the reactor is minimal. During normal operation, the Temelin reactor control system acts to maintain primary temperature in the same way envisioned for IRIS. The Temelin design uses turbine load to select the desired operating temperature, but relies only on the rate-of-change of turbine load for fast transient response. The IRIS control system design proposed in Reference 2 takes the same approach. The Temelin reactor controls do not require or receive any signals indicating whether district heating is in use, so it seems reasonable that the IRIS reactor controls may not require any inputs indicating whether or not extraction steam is being used for desalination, district heating, or other purposes. Naturally, the supervisory control may need to account for the thermal loss to the turbine when setting control system reference values.

3 At maximum district heating load, the Temelin design required less than half of the turbine extraction steam for district heating. Designers could increase the district heating capability on new plants by using more extraction steam and/or using live steam as the heat source. The limit is to use all generated steam for district heating and none for electric generation. Since one normally prefers using low-pressure extraction steam as the district heating heat source, the relationship between district heating power and lost electric generation is nonlinear. 


\section{MULTI-UNIT COORDI NATION}

Reference 2 focused on operating a single unit. When multiple units sit on one site, the primary criteria for operating the set should be an economic one constrained by technological issues.

Consider a site with multiple IRIS NSSS modules. For simplicity, assume that the modules are identical. The cost of operating a single module will have fixed and variable cost components. The fixed costs include capital and non-capital costs. Although capital costs are important, their impact will be included in plant sizing decisions. Once the plant is built, capital costs should not directly affect operating decisions. For example, a combined electric-desalination plant would need a larger, more expensive desalination unit to produce the same fresh water volume if desalination only occurred part time. Once we have built the plant, the desalination unit capital costs no longer affect the decision of how much electricity and fresh water to produce at this minute. The installed desalination capacity, of course, affects the decision as a constraint on the rate at which we can process water. We will treat capital costs as sunk costs and say no more about them. The remaining non-capital fixed costs are, by definition, not affected by how we operate the plant, so they should not affect our operational strategy either. This leaves only the need to consider variable costs.

The variable cost will almost certainly be a monotonically increasing function of operating power - it is hard to imagine that it would be otherwise, especially considering the importance of fuel cost. If the IRIS NSSS module is optimized for full power operation, then the differential operating cost (defined by the slope of the variable cost vs. power curve) will decrease with increasing power. In practice, factors such as turbine admission valve sequencing may not allow the differential cost curve to be monotonic or even continuous over the entire achievable power range. Ideally, the unconstrained differential operating cost curve reaches zero at full power so that full power operation is the optimum economic operating point; invariably it will be positive because the additional power cannot be free.

Now consider operating several NSSSs in parallel to supply a given total power. One goal is to provide the required power at minimum cost. This is a constrained optimization problem. Letting $\mathrm{C}_{\mathrm{i}}\left(\mathrm{P}_{\mathrm{i}}\right)$ be the variable cost associated with operating module $\mathrm{i}$ at power $\mathrm{P}_{\mathrm{i}}$, the optimization problem is to minimize the total cost subject to the total power constraint, i.e.:

$$
\min _{\mathrm{P}_{\mathrm{i}} \mathrm{P}_{\text {oual }}-\sum_{i=1}^{N} \mathrm{P}_{\mathrm{i}}=0} \sum_{\mathrm{i}=1}^{\mathrm{N}} \mathrm{C}_{\mathrm{i}}\left(\mathrm{P}_{\mathrm{i}}\right) \text {. }
$$


Solve this by using Lagrange multipliers. Define the Lagrange function as follows:

$$
\sum_{\mathrm{i}=1}^{\mathrm{N}} \mathrm{C}_{\mathrm{i}}\left(\mathrm{P}_{\mathrm{i}}\right)+\lambda\left(\mathrm{P}_{\text {Total }}-\sum_{\mathrm{i}=1}^{\mathrm{N}} \mathrm{P}_{\mathrm{i}}\right)
$$

A necessary condition for solving the minimization problem is that $\frac{\mathrm{d}_{\mathrm{C}_{\mathrm{i}}}\left(\mathrm{P}_{\mathrm{i}}\right)}{\mathrm{d}_{\mathrm{P}}}-\lambda=0$; i.e., every unit operates at the same differential cost per unit power $\lambda$. If each unit has the same differential cost curve (reasonable for identical units), then the solution is to have each unit operate at the same power; specifically, $P_{i}=\frac{P_{\text {Total }}}{N}$. This simple analysis ignored the maximum and minimum power limits on each module. Although one can easily extend the analysis to include these inequality constraints, the solution is obvious. There are three cases:

1. If $\mathrm{NP}_{\mathrm{i}}^{\text {Min }}<\mathrm{P}_{\text {Total }}<\mathrm{NP}_{\mathrm{i}}^{\text {Max }}$, then we operate each unit at $\mathrm{P}_{\mathrm{i}}=\frac{\mathrm{P}_{\text {Total }}}{\mathrm{N}}$ as before.

2. If $\mathrm{P}_{\text {Total }}>\mathrm{N}_{\mathrm{i}}^{\mathrm{Max}}$, then the plant cannot supply the desired total power. The best it can do is to operate each available unit at full power.

3. If $\mathrm{P}_{\text {Total }}<\mathrm{NP}_{\mathrm{i}}^{\mathrm{Min}}$, then the plant cannot supply the desired total power with all units running. The solution requires shutting down one or more units. Generally, one would shut down as many as possible while still being able to supply the required power.

One should extend the analysis to include time- and site-specific information when that information becomes available. Such information should include short-term operating constraints: for example, refueling unit $i$ is merely a constraint that $\mathrm{P}_{\mathrm{i}}=0$. All solutions, however, have the common feature that the economic optimum operation occurs when the units that are free to do so operate at the same differential cost.

To illustrate the complexity that can arise in even simple applications, consider three units with the following total and differential operating cost characteristics in some fictitious monetary unit §: 

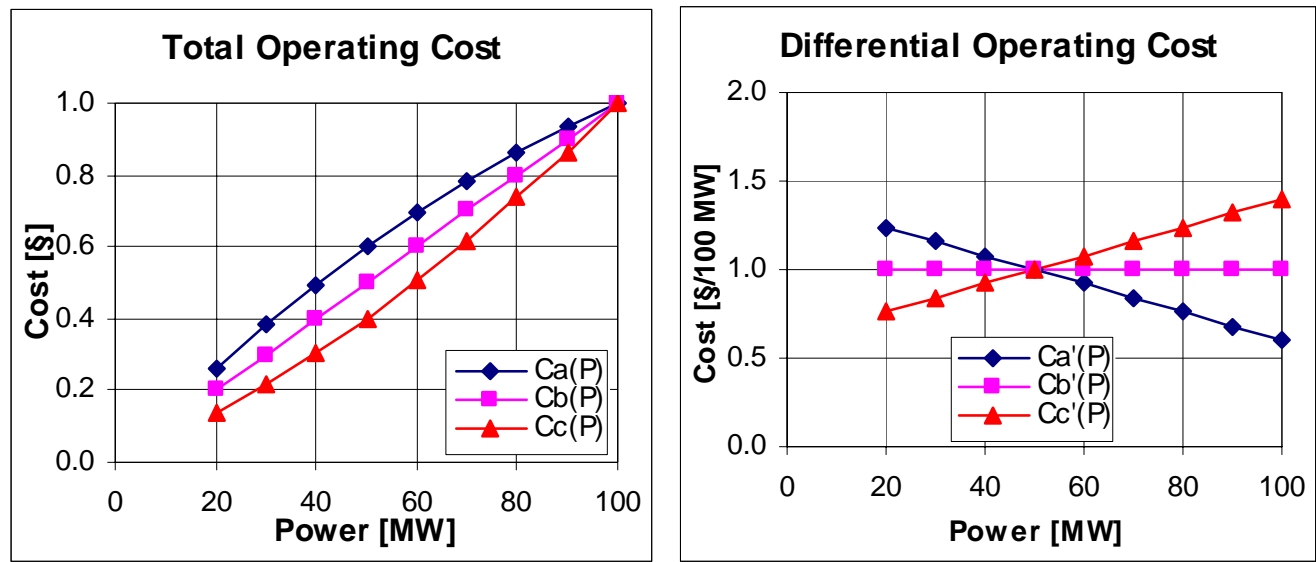

For simplicity, this example assumes that all three units are the same size (100 MW). For constraints, let us assume that each unit could operate continuously between 20 and $100 \mathrm{MW}$. Unit $\mathrm{C}$ is the least expensive at low power, while unit A has the lowest differential cost at high power. The curves assumed the following total cost for each unit:

$$
\left\{\begin{array}{l}
\mathrm{C}_{\mathrm{a}}\left(\mathrm{P}_{\mathrm{a}}\right)=\mathrm{P}_{\mathrm{a}}+4 \mathrm{~h} \mathrm{P}_{\mathrm{a}}\left(1-\mathrm{P}_{\mathrm{a}}\right) \\
\mathrm{C}_{\mathrm{b}}\left(\mathrm{P}_{\mathrm{b}}\right)=\mathrm{P}_{\mathrm{b}} \\
\mathrm{C}_{\mathrm{c}}\left(\mathrm{P}_{\mathrm{c}}\right)=\mathrm{P}_{\mathrm{c}}-4 \mathrm{~h} \mathrm{P}_{\mathrm{c}}\left(1-\mathrm{P}_{\mathrm{c}}\right)
\end{array}\right.
$$

In these equations, powers are in fraction of full power and $h=0.10$ (equivalent to $10 \mathrm{MW}$ ) is the offset from linearity at $50 \%$ power (we will see that the optimum operating strategy is the same for all $0<\mathrm{h} \leq 0.25)$. The associated differential cost curves are as follows:

$$
\left\{\begin{array}{l}
\frac{d_{C_{a}}\left(P_{a}\right)}{d P_{a}}=1+4 h\left(1-2 P_{a}\right) \\
\frac{d C_{b}\left(P_{b}\right)}{d P_{b}}=1 \\
\frac{d C_{c}\left(P_{c}\right)}{d P_{c}}=1-4 h\left(1-2 P_{c}\right)
\end{array}\right.
$$

These three units can produce any combination from 20 to $300 \mathrm{MW}$. The optimal cost solution has seven constraints: a minimum and a maximum for each unit and a total power constraint. Carrying out the calculations results in the following loading plan:

1. From 20 to $50 \mathrm{MW}$, use unit $\mathrm{C}$ since it is the cheapest unit to operate.

2. The differential operating cost of unit B is less than that of unit $\mathrm{C}$ when unit $\mathrm{C}$ is operating at more than $50 \mathrm{MW}$, but since the 
minimum allowable load on unit $\mathrm{C}$ is $20 \mathrm{MW}$, we should continue to use unit $\mathrm{C}$ alone up to $60 \mathrm{MW}$. At $60 \mathrm{MW}$, it is cheaper to bring unit $\mathrm{B}$ on line than it is to increase power from unit C. From 60 to $70 \mathrm{MW}$, use unit $\mathrm{B}$ for $20 \mathrm{MW}$, and unit $\mathrm{C}$ for the remainder.

3. At $70 \mathrm{MW}$, unit $\mathrm{C}$ has reached $50 \mathrm{MW}$ and the differential cost curves show that it is cheaper to increase power on unit $B$ than on unit C. From 70 to $150 \mathrm{MW}$, use unit C for $50 \mathrm{MW}$, and unit B for the remainder. From 150 to $160 \mathrm{MW}$, use unit B for $100 \mathrm{MW}$, and unit $\mathrm{C}$ for the remainder.

4. At $160 \mathrm{MW}$ it becomes cheaper to operate unit A at full power and make up the difference with the others. From 160 to 300 MW, operate unit A at full output and make up the remainder as indicated in steps 2 or 3 as appropriate.

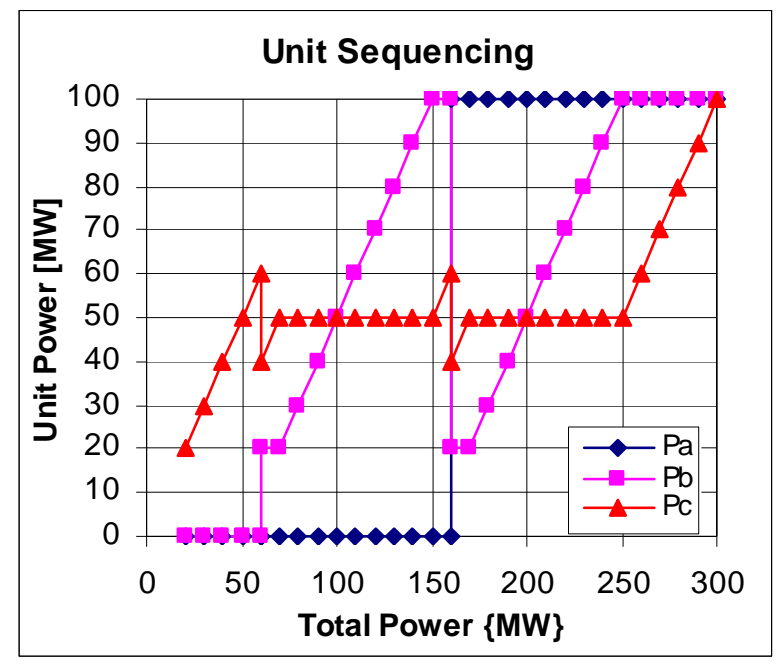

As we see, rather simple economic parameters can lead to moderately complex operating strategies if the units are not identical. Even with smooth operating cost curves, the constraints can lead to significant discontinuities in how the optimum power generation mix varies with total required power. This example did not consider the cost of starting a unit or shutting one down, nor the constraints on doing so. For example, xenon transients may prevent restarting a unit shortly after it shuts down. Startup and shutdown also increase operator workload, and some tasks (particularly bringing a reactor critical and synchronizing a generator) should probably demand operator action, even if only to provide permission.

Although there are complexities not considered in this example, methods for determining the optimum are straightforward and well known. Reference 6 provides many details. The optimization algorithms work best when they 
account for the current plant operating limits. In the early 1980's, Westinghouse developed a Remote Dispatch Interface System that provided the information that a remote dispatch computer would need to incorporate unit operating constraints into the economic optimization. IRIS could use a similar system for each unit, and combine the results at the site Supervisory Control level, interfacing with remote dispatching as if the site were a single unit. The Supervisory Control would then perform site optimization locally. The concept could extend naturally to incorporate other proposed uses such as providing steam for desalination or district heating.

If one operating crew has to monitor multiple units, operating and maneuvering all units at the same power may or may not be the optimal arrangement from a human factors perspective. Task 5 addressing human factors should consider this issue. 


\section{FUNCTI ONAL REQUI REMENTS: PLANT MANEUVERI NG CAPABI LITY}

This section identifies the plant maneuverability requirements for normal power operation and selected abnormal conditions (specifically, abnormal conditions that do not involve damage to plant equipment as the initiating event), as well as reference events identified to provide a robust design. The discussions describe the relevant event and then define the precise conditions assumed for its initiation and successful compliance. Figure 1 provides a simplified view of the requirements.

The IRIS design is not finalized, and there is considerable opportunity to modify or change the design. These requirements reflect the following assumptions:

- There are no pressurizer relief valves.

- There are no steam line safety valves upstream of the isolation valves, but there are safety valves in the lower-pressure piping downstream of the isolation valves.

- There are no steam line relief valves upstream of the isolation valves, but there are relief valves in the lower-pressure piping downstream of the isolation valves.

The following subsections follow a standardized requirements format. We use one subsection for each event type, and write each event subsection in a standalone manner. Although this leads to some repeating some description and some requirement text, the additional rigor helps ensure that each requirement has one and only one application; thereby facilitating design verification. Each event subsection begin with introductory text that provides background information and defines any necessary terms and/or conditions. The second part is a list of detailed requirements, starting with a formal requirement identifier. Sometimes we provide qualifiers (such as guidance or exception statements) to clarify specific requirements.

Except for a few obvious exceptions (e.g., 100\%, 24 hours), ALL numerical values in this section are preliminary and subject to change. We included them to give an indication of their possible magnitude, but we must perform the necessary and appropriate trade-off studies before accepting any of these as final. 


\subsection{NORMAL EVENTS}

\subsubsection{ROUTINE POWER OPERATION}

\subsubsection{LOAD FOLLOW}

Daily load follow refers to 24-hour cycles operating at high power during periods of low demand and reducing load during periods of low demand. Many nuclear units avoid load follow, some load follow only on weekends, and others may load follow daily. From a control systems perspective, the ramp load changes bound the transients that normal load follow imposes on the reactor coolant system, steam generator, secondary system, and turbine. Daily load follow leads to power distribution and xenon-135 transients in the core. The core designers must accommodate these in designing their core operating strategy.

Typical design load follow patterns involve operating at full power during the day, then ramping to a lower power over several hours, remaining at the low power (typically $50 \%$ ) overnight, and then slowly ramping back to full power. Six hours at low power not only approximates realistic utility demands, but also approximates the most limiting time from a xenon transient perspective.

The design basis load follow pattern consists of one or more repetitions of identical 24-hour patterns that meet the following criteria, followed by three days of full power operation:

- Generated electrical power ramps from 100 percent to 50 percent in 2 hours, and then

- Generated electrical power remains at 50 percent for 2 to 10 hours, and then

- Generated electrical power ramps from 50 percent to 100 percent in 2 hours, and then

- Generated electrical power remains at 100 percent for the remainder of the 24-hour cycle (i.e., 18 to 10 hours).

The conditions for the design-basis load follow are as follows:

- The load changes results from operator requests to the turbine control system.

- The load following occurs in the first $90 \%$ of the core cycle.

- The plant initial condition is quasi-steady state.

- All relevant process variables begin at their nominal values for the initial plant power.

- All relevant plant systems are operational and remain so. 
- All relevant I\&C systems are in automatic control.

The specific requirements defining acceptable responses to daily load follow operations (from a control and operations perspective) are as follows:

[IRIS.DailyLoadFollow.1] The IRIS plant shall be able to perform the designbasis load follow pattern.

[IRIS.DailyLoadFollow.1.1] The IRIS plant shall be able to perform the design-basis load follow pattern without manual intervention.

Exception: (1) The operator may enter commands that define and request following a daily load follow pattern. (2) The operator may define the desired target axial offset (or equivalent) versus power and/or time. (3) The operator may make boron concentration reductions to account for core burnup.

[IRIS.DailyLoadFollow.1.2] The transient resulting from the design-basis load follow pattern shall not create diverging oscillations in any plant process variables (i.e. temperatures, pressures, flows, levels, etc.).

[IRIS.DailyLoadFollow.1.3] The transient resulting from the design-basis load follow pattern shall not cause a reactor trip.

[IRIS.DailyLoadFollow.1.4] The transient resulting from the design-basis load follow pattern shall not cause ESF actuation.

[IRIS.DailyLoadFollow.1.5] The transient resulting from the design-basis load follow pattern shall not cause a turbine trip.

[IRIS.DailyLoadFollow.1.6] The transient resulting from the design-basis load follow pattern shall not cause a turbine runback.

[IRIS.DailyLoadFollow.1.7] The transient resulting from the design-basis load follow pattern shall not cause a generator trip.

[IRIS.DailyLoadFollow.1.8] The transient resulting from the design-basis load follow pattern shall not cause a grid disconnect.

[IRIS.DailyLoadFollow.1.9] The transient resulting from the design-basis load follow pattern shall not cause any pressurizer safety valves to open.

[IRIS.DailyLoadFollow.1.10] The transient resulting from the design-basis load follow pattern shall not cause any steam line safety valves to open.

[IRIS.DailyLoadFollow.1.11] The transient resulting from the design-basis load follow pattern shall not cause any steam line relief valves to open.

[IRIS.DailyLoadFollow.1.12] The transient resulting from the design-basis load follow pattern shall not cause any turbine bypass valves to open.

[IRIS.DailyLoadFollow.1.13] The transient resulting from the design-basis load follow pattern shall not uncover the pressurizer heaters. 
[IRIS.DailyLoadFollow.1.14] The transient resulting from the design-basis load follow pattern shall not cause high frequency rod stepping.

[IRIS.DailyLoadFollow.1.15] The transient resulting from the design-basis load follow pattern shall not cause any neutron flux signals used for automatic control or protection to exceed the value corresponding to $103 \%$ of licensed power.

Exception: This requirement applies only to design analyses. It does not apply to plant startup tests.

[IRIS.DailyLoadFollow.1.16] The transient resulting from the design-basis load follow pattern shall not cause the parameter used to initiate the transient to overshoot or undershoot its settings by more than $30 \%$ of the setting change of the setting change required to initiate a $10 \%$ or $10 \%$ step.

[IRIS.DailyLoadFollow.1.17] The transient resulting from the design-basis load follow pattern shall not cause the steam superheat at the turbine inlet to drop below 25 Celsius degrees.

[IRIS.DailyLoadFollow.1.18] The IRIS plant shall not require CVCS boration or dilution operations for axial offset control during load follow operation.

Exception: Dilution to account for burnup is permitted, and may be timed to assist in power distribution control.

[IRIS.DailyLoadFollow.1.19] The I\&C System shall provide for automatic axial offset control during load follow operation.

Guidance: The operator may define the desired target axial offset (or equivalent) versus power and/or time. The preference is to provide automatic axial offset target definition.

\subsubsection{DISPATCHED LOAD CHANGES}

Grid frequency control is one of the most important factors in maintaining electric grid stability, since grid frequency is the fundamental indicator for determining the balance between generation and consumption. Nuclear units may not participate in controlling grid frequency on large grids, but frequency control capability will be essential for small grids and grids with a high nuclear generating component. Power plants have three means to address variations in grid frequency: remote load dispatching, and local frequency control. Local frequency control occurs when the turbine control system uses a frequency corrector to respond to grid frequency changes. Unless the grid is particularly small, these variations are usually negligible. Remote load dispatching involves larger changes that result when a central office coordinates grid power generation. The load change requests may be performed by the operator (as discussed earlier) or automatically (as in this section). One normally assumes 
that the plant remains connected to an infinite grid. The load changes associated with remote load dispatching are generally slower than those associated with local frequency control, but often involve larger power changes, making them more limiting from a design perspective. This imposes severe transients on the plant, and component wear and fatigue become major concerns. Typical design limits involve $\pm 5 \%$ fluctuations, and restrict or forbid remote load dispatching near full power. The frequency spectrum associated with the power changes is critical, and most utilities do not have the information needed to specify what their needs are in a useful form.

The design-basis dispatched load change pattern involves small changes in power satisfying the following conditions:

- Dispatched load changes involve small remotely-generated changes in demanded electrical power generation.

- Dispatched load change may be superimposed on either (1) a constant power demand or (2) the ramp power changes that occur during the design basis load follow pattern (both capabilities required).

- Dispatched load changes may occur simultaneously with frequency control.

- Demanded electric power remains between 50 and 100 percent at all times.

- The demanded power changes are equivalent to a stochastic process with a normalized autocorrelation function $\mathrm{R}(\mathrm{T})=1.25 \operatorname{Exp}[-\mathrm{Abs}(\mathrm{T} / 5)]-0.25$ $\operatorname{Exp}[-\mathrm{Abs}(\mathrm{T} / 1)]$ followed by hard limits. $\mathrm{T}$ is given in minutes. (The description of the stochastic process given here is based on its simplicity rather than on known needs. We should gather hard data to define this better).

- The magnitude of the non-limited power change request does not exceed \pm 3.5 percent rms.

- The limited power changes do not exceed $\pm 5.0 \%$ (i.e., peak-to-peak changes do not exceed 10\%).

- Dispatched load changes about a constant power demand can occur at any time during the core cycle.

- Dispatched load changes about the design basis load follow pattern can occur at any time in the core cycle that the design basis load follow pattern is permitted and achievable (i.e., at least the first $90 \%$ of the core cycle).

- The plant initial condition is quasi-steady state (transients associated with daily load follow excepted, e.g., I-135 and Xe-135 need not be in steady state). 
- All relevant process variables begin at their nominal values for the initial plant power.

- All relevant plant systems are operational and remain so.

- All relevant I\&C systems are in automatic control.

The specific requirements defining acceptable responses to dispatched load change operations (from a control and operations perspective) are as follows:

[IRIS.DispatchedLoadChange.1] The IRIS plant shall be able to perform the design-basis dispatched load change pattern.

[IRIS.DispatchedLoadChange.1.1] The IRIS plant shall be able to perform the design-basis dispatched load change pattern without requiring manual intervention.

Exception: Routine operations associated with the underlying daily load follow.

[IRIS.DispatchedLoadChange.1.2] The transient resulting from the designbasis dispatched load change pattern shall not create diverging oscillations in any plant process variables (i.e. temperatures, pressures, flows, levels, etc.).

[IRIS.DispatchedLoadChange.1.3] The transient resulting from the designbasis dispatched load change pattern shall not cause a reactor trip.

[IRIS.DispatchedLoadChange.1.4] The transient resulting from the designbasis dispatched load change pattern shall not cause ESF actuation.

[IRIS.DispatchedLoadChange.1.5] The transient resulting from the designbasis dispatched load change pattern shall not cause a turbine trip.

[IRIS.DispatchedLoadChange.1.6] The transient resulting from the designbasis dispatched load change pattern shall not cause a turbine runback.

[IRIS.DispatchedLoadChange.1.7] The transient resulting from the designbasis dispatched load change pattern shall not cause a generator trip.

[IRIS.DispatchedLoadChange.1.8] The transient resulting from the designbasis dispatched load change pattern shall not cause a grid disconnect.

[IRIS.DispatchedLoadChange.1.9] The transient resulting from the designbasis dispatched load change pattern shall not cause any pressurizer safety valves to open.

[IRIS.DispatchedLoadChange.1.10] The transient resulting from the designbasis dispatched load change pattern shall not cause any steam line safety valves to open.

[IRIS.DispatchedLoadChange.1.11] The transient resulting from the designbasis dispatched load change pattern shall not cause any steam line relief valves to open. 
[IRIS.DispatchedLoadChange.1.12] The transient resulting from the designbasis dispatched load change pattern shall not cause any turbine bypass valves to open.

[IRIS.DispatchedLoadChange.1.13] The transient resulting from the designbasis dispatched load change pattern shall not uncover the pressurizer heaters.

[IRIS.DispatchedLoadChange.1.14] The transient resulting from the designbasis dispatched load change pattern shall not cause high frequency rod stepping.

[IRIS.DispatchedLoadChange.1.15] The transient resulting from the designbasis dispatched load change pattern shall not cause any neutron flux signals used for automatic control or protection to exceed the value corresponding to $103 \%$ of licensed power.

Exception: This requirement applies only to design analyses. It does not apply to plant startup tests.

[IRIS.DispatchedLoadChange.1.17] The transient resulting from the designbasis dispatched load change pattern shall not cause the steam superheat at the turbine inlet to drop below 25 Celsius degrees.

[IRIS.DispatchedLoadChange.1.18] The IRIS plant shall not require CVCS boration or dilution operations for automatic axial offset control during design-basis dispatched load operations.

Exception: Dilution to account for burnup is permitted, and may be timed to assist in power distribution control.

[IRIS.DispatchedLoadChange.1.19] The I\&C System shall provide for automatic axial offset control during design-basis dispatched load operations.

\subsubsection{FREQUENCY CONTROL}

Grid frequency control is one of the most important factors in maintaining electric grid stability, since grid frequency is the fundamental indicator for determining the balance between generation and consumption. Nuclear units may not participate in controlling grid frequency on large grids, but frequency control capability will be essential for small grids and grids with a high nuclear generating component. Power plants have three means to address variations in grid frequency: remote load dispatching, and local frequency control. Local frequency control occurs when the turbine control system uses a frequency corrector to respond to grid frequency changes. Unless the grid is particularly small, these variations are usually negligible. Typical design limits involve $\pm 1 \%$ rms fluctuations, and restrict increases above full power. The frequency spectrum associated with the power changes is critical, and most utilities do 
not have the information needed to specify what their needs are in a useful form.

The design-basis frequency control pattern involves small changes in power satisfying the following conditions:

- Frequency control involves small locally-derived changes in power demand to the turbine. These changes are proportional to deviations in grid frequency with a 4 percent frequency deviation corresponding to a 100 percent power change.

- Frequency control may be superimposed on either (1) a constant power demand or (2) the ramp power changes that occur during the design basis load follow pattern (both capabilities required).

- Frequency control may occur simultaneously with dispatched load changes.

- Demanded electric power remains between 20 and 100 percent at all times.

- The demanded power changes are equivalent to a stochastic process with a normalized autocorrelation function $\mathrm{R}(\mathrm{T})=(2 / 9) \operatorname{Exp}[-\mathrm{Abs}(\mathrm{T} / 5)]+(7 / 9)$ $\operatorname{Exp}[-\operatorname{Abs}(\mathrm{T} / 0.5)] . \mathrm{T}$ is given in minutes. (The description of the stochastic process given here is based on its simplicity rather than on known needs. We should gather hard data to define this better).

- The magnitude of the power changes does not exceed \pm 1.0 percent $\mathrm{rms}$.

- The frequency control about a constant power demand can occur at any time during the core cycle.

- The frequency control about the design basis load follow pattern can occur at any time in the core cycle that the design basis load follow pattern is permitted and achievable (i.e., at least the first $90 \%$ of the core cycle).

- The plant initial condition is quasi-steady state (transients associated with daily load follow excepted, e.g., I-135 and Xe-135 need not be in steady state).

- All relevant process variables begin at their nominal values for the initial plant power.

- All relevant plant systems are operational and remain so.

- All relevant I\&C systems are in automatic control.

The specific requirements defining acceptable responses to frequency control operations (from a control and operations perspective) are as follows:

[IRIS.FrequencyControl.1] The IRIS plant shall be able to perform the designbasis frequency control pattern. 
[IRIS.FrequencyControl.1.1] The IRIS plant shall be able to perform the design-basis frequency control pattern without requiring manual intervention.

Exception: Routine operations associated with the underlying daily load follow.

[IRIS.FrequencyControl.1.2] The transient resulting from the design-basis frequency control pattern shall not create diverging oscillations in any plant process variables (i.e. temperatures, pressures, flows, levels, etc.).

[IRIS.FrequencyControl.1.3] The transient resulting from the design-basis frequency control pattern shall not cause a reactor trip.

[IRIS.FrequencyControl.1.4] The transient resulting from the design-basis frequency control pattern shall not cause ESF actuation.

[IRIS.FrequencyControl.1.5] The transient resulting from the design-basis frequency control pattern shall not cause a turbine trip.

[IRIS.FrequencyControl.1.6] The transient resulting from the design-basis frequency control pattern shall not cause a turbine runback.

[IRIS.FrequencyControl.1.7] The transient resulting from the design-basis frequency control pattern shall not cause a generator trip.

[IRIS.FrequencyControl.1.8] The transient resulting from the design-basis frequency control pattern shall not cause a grid disconnect.

[IRIS.FrequencyControl.1.9] The transient resulting from the design-basis frequency control pattern shall not cause any pressurizer safety valves to open.

[IRIS.FrequencyControl.1.10] The transient resulting from the design-basis frequency control pattern shall not cause any steam line safety valves to open.

[IRIS.FrequencyControl.1.11] The transient resulting from the design-basis frequency control pattern shall not cause any steam line relief valves to open.

[IRIS.FrequencyControl.1.12] The transient resulting from the design-basis frequency control pattern shall not cause any turbine bypass valves to open.

[IRIS.FrequencyControl.1.13] The transient resulting from the design-basis frequency control pattern shall not uncover the pressurizer heaters.

[IRIS.FrequencyControl.1.14] The transient resulting from the design-basis frequency control pattern shall not cause high frequency rod stepping.

[IRIS.FrequencyControl.1.15] The transient resulting from the design-basis frequency control pattern shall not cause any neutron flux signals used 
for automatic control or protection to exceed the value corresponding to $103 \%$ of licensed power.

Exception: This requirement applies only to design analyses. It does not apply to plant startup tests.

[IRIS.FrequencyControl.1.16] The transient resulting from the design-basis frequency control pattern shall not cause the steam superheat at the turbine inlet to drop below 25 Celsius degrees.

[IRIS.FrequencyControl.1.17] The IRIS plant shall not require CVCS boration or dilution operations for automatic axial offset control during designbasis frequency control operation.

Exception: Dilution to account for burnup is permitted, and may be timed to assist in power distribution control.

[IRIS.FrequencyControl.1.18] The I\&C System shall provide for automatic axial offset control during design-basis frequency control operation.

\subsubsection{SPECIAL EVENTS}

\subsubsection{SYNCHRONIZATION}

Generator synchronization leads to an immediate need to increase turbine load to the minimum allowable value for continued operation. The load pickup required normally exceeds NSSS loading limits. To avoid exceeding these limits, normal practice is to preload the NSSS by using the turbine bypass system. As the turbine picks up load, the turbine bypass valves should close accordingly.

The definition of the design-basis synchronization is as follows:

- The initiating event is a generator synchronization command (either (1) a manual command or (2) an automatic command following a manually issued permissive).

- The normal generator synchronization can occur at any time during the core cycle.

- The plant initial condition is quasi-steady state with the initial NSSS power set greater than the power required for the post-synchronization turbine loading.

- All relevant process variables begin at their nominal values for the initial plant power.

- All relevant plant systems are operational and remain so.

- All relevant I\&C systems are in automatic control.

The specific requirements defining acceptable responses to synchronization operations (from a control and operations perspective) are as follows: 
[IRIS.Synchronization.1] The IRIS plant shall be able to perform the designbasis synchronization.

[IRIS.Synchronization.1.1] The transient resulting from the design-basis synchronization shall bring the plant to a quasi-steady state condition with the turbine operating above minimum load, without manual intervention.

[IRIS.Synchronization. 1.2] The transient resulting from the design-basis synchronization shall not create diverging oscillations in any plant process variables (i.e., temperatures, pressures, flows, levels, etc.).

[IRIS.Synchronization.1.3] The transient resulting from the design-basis synchronization shall not cause a reactor trip.

[IRIS.Synchronization.1.4] The transient resulting from the design-basis synchronization shall not cause ESF actuation.

[IRIS.Synchronization. 1.5] The transient resulting from the design-basis synchronization shall not cause a turbine trip.

[IRIS.Synchronization.1.6] The transient resulting from the design-basis synchronization shall not cause a turbine runback.

[IRIS.Synchronization.1.7] The transient resulting from the design-basis synchronization shall not cause a generator trip.

[IRIS.Synchronization.1.8] The transient resulting from the design-basis synchronization shall not cause a grid disconnect.

[IRIS.Synchronization.1.9] The transient resulting from the design-basis synchronization shall not cause any pressurizer safety valves to open.

[IRIS.Synchronization.1.10] The transient resulting from the design-basis synchronization shall not cause any steam line safety valves to open.

[IRIS.Synchronization.1.11] The transient resulting from the design-basis synchronization shall not cause any steam line relief valves to open.

[IRIS.Synchronization.1.12] The transient resulting from the design-basis synchronization shall stabilize with the turbine bypass valves closed.

[IRIS.Synchronization.1.13] The transient resulting from the design-basis synchronization shall not uncover the pressurizer heaters.

[IRIS.Synchronization.1.14] The transient resulting from the design-basis synchronization shall not cause high frequency rod stepping.

[IRIS.Synchronization.1.15] The transient resulting from the design-basis synchronization shall not cause any neutron flux signals used for automatic control or protection to exceed the value corresponding to $103 \%$ of licensed power.

Exception: This requirement applies only to design analyses. It does not apply to plant startup tests. 


\subsubsection{SHORT-TERM LOAD INCREASE}

Utilities desire having the capability to correct overloads of lines tying the grids together and, hence, prevent grid breakup. To address this desire, they defined the short-term load increase requirements contained here, and placed those requirements in the "Utility Requirements Document" which gave requirements for the AP600. The URD was ambiguous in defining exactly what the intended event was. Apparently, the focus was on making a $20 \%$ power change within ten minutes of identifying the need for the change. At one point, the URD clearly implied that the grid would remain connected; therefore, the specification was not for handling islanding situations. The expectation is that this capability would be useful during the later life of the plant when it may not be the most economical plant and, hence, not base-loaded. Requirements for the companion event (involving for load decreases) appear later.

The definition of the design-basis short-term load increase is as follows:

- A load change results from an operator request to the supervisory control system.

- The load change request is for a monotonic increase in demanded power generation of up to $20 \%$ in 10 minutes. (The requirement is that there must be one acceptable monotonic increase, not that all monotonic increases are acceptable).

- The initial plant electrical output is at least $20 \%$ and less than $100 \%$. (If the initial power is greater than $80 \%$, the intent is that full power be achievable).

- The final demanded electrical output does not exceed $100 \%$.

- The load increase can occur at any time during the core cycle.

- The plant initial condition is quasi-steady state (transients associated with daily load follow excepted, e.g., I-135 and Xe-135 need not be in steady state).

- The plant has been operating within its design basis load follow capability and using the design load follow operating strategy for the previous 72 hours.

- All relevant process variables begin at their nominal values for the initial plant power.

- All relevant plant systems are operational and remain so.

- All relevant I\&C systems are in automatic control.

- The initial control rod position provides for adequate rod withdrawal during the resulting transient.

This definition does not permit limiting the magnitude of the increase because of core power distribution limits, so it is reasonable to assume that the plant is 
operating within the core's design basis load follow capability. The 72-hour assumption ensures that the core iodine-135 and xenon-135 distributions are consistent with the load follow capability. Similarly, this definition does not permit limiting the magnitude of the increase because of turbine stress limits.

The specific requirements defining acceptable responses to short-term load increases (from a control and operations perspective) are as follows:

[IRIS.LoadIncrease.1] The IRIS plant shall be able to perform the design-basis short-term load increase.

[IRIS.LoadIncrease.1.1] The transient resulting from the design-basis shortterm load increase shall bring the plant to a quasi-steady state condition without manual intervention.

[IRIS.LoadIncrease.1.2] The transient resulting from the design-basis shortterm load increase shall not create diverging oscillations in any plant process variables (i.e. temperatures, pressures, flows, levels, etc.).

[IRIS.LoadIncrease.1.3] The transient resulting from the design-basis shortterm load increase shall not cause a reactor trip.

[IRIS.LoadIncrease.1.4] The transient resulting from the design-basis shortterm load increase shall not cause ESF actuation.

[IRIS.LoadIncrease.1.5] The transient resulting from the design-basis shortterm load increase shall not cause a turbine trip.

[IRIS.LoadIncrease.1.6] The transient resulting from the design-basis shortterm load increase shall not cause a turbine runback.

[IRIS.LoadIncrease.1.7] The transient resulting from the design-basis shortterm load increase shall not cause a generator trip.

[IRIS.LoadIncrease.1.8] The transient resulting from the design-basis shortterm load increase shall not cause a grid disconnect.

[IRIS.LoadIncrease.1.9] The transient resulting from the design-basis shortterm load increase shall not cause any pressurizer safety valves to open.

[IRIS.LoadIncrease.1.10] The transient resulting from the design-basis short-term load increase shall not cause any steam line safety valves to open.

[IRIS.LoadIncrease.1.11] The transient resulting from the design-basis short-term load increase shall not cause any steam line relief valves to open.

[IRIS.LoadIncrease.1.12] The transient resulting from the design-basis short-term load increase shall not cause any turbine bypass valves to open. 
[IRIS.LoadIncrease.1.13] The transient resulting from the design-basis short-term load increase shall not uncover the pressurizer heaters.

[IRIS.LoadIncrease.1.14] The transient resulting from the design-basis short-term load increase shall not cause high frequency rod stepping.

[IRIS.LoadIncrease.1.15] The transient resulting from the design-basis short-term load increase shall not cause any neutron flux signals used for automatic control or protection to exceed the value corresponding to $103 \%$ of licensed power.

Exception: This requirement applies only to design analyses. It does not apply to plant startup tests.

[IRIS.LoadIncrease.1.16] The transient resulting from the design-basis short-term load increase shall not cause the parameter used to initiate the transient to overshoot its final setting by more than $30 \%$ of the setting change of the setting change required to initiate a $10 \%$ step.

Exception: This requirement applies only to design analyses. It does not apply to plant startup tests.

[IRIS.LoadIncrease.1.17] The transient resulting from the design-basis short-term load increase shall not cause the steam superheat at the turbine inlet to drop below 25 Celsius degrees.

\subsubsection{SHORT-TERM LOAD DECREASE}

Utilities desire having the capability to correct overloads of lines tying the grids together and, hence, prevent grid breakup. , and placed those requirements in the "Utility Requirements Document" which gave requirements for the AP600. The URD was ambiguous in defining exactly what the intended event was. Apparently, the focus was on making a $20 \%$ power change within ten minutes of identifying the need for the change. At one point, the URD clearly implied that the grid would remain connected; therefore, the specification was not for handling islanding situations. The expectation is that this capability would be useful during the later life of the plant when it may not be the most economical plant and, hence, not base-loaded. Requirements for the companion event (involving for load increases) appeared earlier.

The definition of the design-basis short-term load decrease is as follows:

- A load change results from an operator request to the supervisory control system.

- The load change request is for a monotonic decrease in demanded power generation of up to $-20 \%$ in 10 minutes. (The requirement is that there must be one acceptable monotonic decrease, not that all monotonic increases are acceptable). 
- The initial plant electrical output is greater than $20 \%$ and no more than $100 \%$

- The final demanded plant electrical output is no less than $20 \%$

- The load decrease can occur at any time during the core cycle.

- The plant initial condition is quasi-steady state (transients associated with daily load follow excepted, e.g., I-135 and Xe-135 need not be in steady state).

- The plant has been operating within its design basis load follow capability and using the design load follow operating strategy for the previous 72 hours. (This accounts for turbine thermal stress limits as well as core limits).

- All relevant process variables begin at their nominal values for the initial plant power.

- All relevant plant systems are operational and remain so.

- All relevant I\&C systems are in automatic control.

Note that definition does not permit limiting the magnitude of the increase because of core power distribution limits, so it is reasonable to assume that the plant is operating within the core's design basis load follow capability. The 72hour assumption ensures that the core iodine-135 and xenon-135 distributions are consistent with the load follow capability. Similarly, this definition does not permit limiting the magnitude of the decrease because of turbine stress limits.

The specific requirements defining acceptable responses to short-term load decreases (from a control and operations perspective) are as follows:

[IRIS.LoadDecrease.1] The IRIS plant shall be able to perform the design-basis short-term load decrease.

[IRIS.LoadDecrease.1.1] The transient resulting from the design-basis shortterm load decrease shall bring the plant to a quasi-steady state condition without manual intervention.

[IRIS.LoadDecrease.1.2] The transient resulting from the design-basis shortterm load decrease shall not create diverging oscillations in any plant process variables (i.e. temperatures, pressures, flows, levels, etc.).

[IRIS.LoadDecrease.1.3] The transient resulting from the design-basis shortterm load decrease shall not cause a reactor trip.

[IRIS.LoadDecrease.1.4] The transient resulting from the design-basis shortterm load decrease shall not cause ESF actuation.

[IRIS.LoadDecrease.1.5] The transient resulting from the design-basis shortterm load decrease shall not cause a turbine trip. 
[IRIS.LoadDecrease.1.6] The transient resulting from the design-basis shortterm load decrease shall not cause a turbine runback.

[IRIS.LoadDecrease.1.7] The transient resulting from the design-basis shortterm load decrease shall not cause a generator trip.

[IRIS.LoadDecrease.1.8] The transient resulting from the design-basis shortterm load decrease shall not cause a grid disconnect.

[IRIS.LoadDecrease.1.9] The transient resulting from the design-basis shortterm load decrease shall not cause any pressurizer safety valves to open.

[IRIS.LoadDecrease.1.10] The transient resulting from the design-basis short-term load decrease shall not cause any steam line safety valves to open.

[IRIS.LoadDecrease.1.11] The transient resulting from the design-basis short-term load decrease shall not cause any steam line relief valves to open.

[IRIS.LoadDecrease.1.12] The transient resulting from the design-basis short-term load decrease shall not cause any turbine bypass valves to open.

[IRIS.LoadDecrease.1.13] The transient resulting from the design-basis short-term load decrease shall not uncover the pressurizer heaters.

[IRIS.LoadDecrease.1.14] The transient resulting from the design-basis short-term load decrease shall not cause high frequency rod stepping.

[IRIS.LoadDecrease.1.15] The transient resulting from the design-basis short-term load decrease shall not cause any neutron flux signals used for automatic control or protection to exceed the value corresponding to $103 \%$ of licensed power.

Exception: This requirement applies only to design analyses. It does not apply to plant startup tests.

[IRIS.LoadDecrease.1.16] The transient resulting from the design-basis short-term load decrease shall not cause the parameter used to initiate the transient to undershoot its final setting by more than $30 \%$ of the setting change of the setting change required to initiate a $-10 \%$ step.

Exception: This requirement applies only to design analyses. It does not apply to plant startup tests.

[IRIS.LoadDecrease.1.17] The transient resulting from the design-basis short-term load decrease shall not cause the steam superheat at the turbine inlet to drop below 25 Celsius degrees. 


\subsection{UPSETEVENTS}

\subsubsection{EXTERNAL ELECTRICAL DISTURBANCES}

\subsubsection{GRID ISLANDING - INCREASE}

A grid disturbance outside the plant can separate the plant from the infinite grid, and lead to a change in the generator load. This section considers transients where the load increases. In general, the load change occurs as a step. The magnitude of the change is not known in advance, and there is no practical way to measure it directly. Except for the most trivial load changes, the resulting mismatch between generation and load will result in a negative turbine/generator acceleration. the rate and magnitude of the acceleration depends on the size of the island and its load composition, especially the fraction of loads represented by rotating equipment. The actions of load shedding equipment outside the plant has a strong effect on how the transient progresses. Given the uncertainties, it is impractical to guarantee that the plant can survive islanding under all reasonable circumstances, so one must simply specify a design basis event. Testing a plant's ability to handle grid islanding is impractical, so the designers must rely on calculations.

The definition of the design-basis island mode increase is as follows:

- The generator is initially delivering power at rated power factor to a finite grid with a grid load pickup factor of between (1) 1.17 to 3.5 percent load per Hertz for $60 \mathrm{~Hz}$ grids, or (2) 1.4 to 4.2 percent load per Hertz for 50 $\mathrm{Hz}$ grids.

- The load change appears as step increase in electrical load of no more than 10 percent.

- The initial plant electrical output is between 20 and 100 percent.

- The final grid power consumption does not exceed 100 percent at rated frequency.

- The grid islanding load increase can occur at any time during the core cycle.

- The plant initial condition is quasi-steady state.

- All relevant process variables begin at their nominal values for the initial plant power.

- All relevant plant systems are operational and remain so.

- All relevant I\&C systems are in automatic control.

- The initial control rod position provides for adequate rod withdrawal during the resulting transient.

- The grid island does NOT have load shedding equipment. 
The specific requirements defining acceptable responses to grid islanding load increases (from a control and operations perspective) are as follows:

[IRIS.Islanding. 1] The IRIS plant shall be able to perform the design-basis grid islanding load increase.

[IRIS.Islanding.1.1] The transient resulting from the design-basis grid islanding load increase shall bring the plant to a quasi-steady state condition without manual intervention.

[IRIS.Islanding.1.2] The transient resulting from the design-basis grid islanding load increase shall not create diverging oscillations in any plant process variables (i.e. temperatures, pressures, flows, levels, etc.).

[IRIS.Islanding.1.3] The transient resulting from the design-basis grid islanding load increase shall not cause a reactor trip.

[IRIS.Islanding. 1.4] The transient resulting from the design-basis grid islanding load increase shall not cause ESF actuation.

[IRIS.Islanding.1.5] The transient resulting from the design-basis grid islanding load increase shall not cause a turbine trip.

[IRIS.Islanding.1.6] The transient resulting from the design-basis grid islanding load increase shall not cause a turbine runback.

[IRIS.Islanding.1.7] The transient resulting from the design-basis grid islanding load increase shall not cause a generator trip.

[IRIS.Islanding. 1.8] The transient resulting from the design-basis grid islanding load increase shall not cause a grid disconnect.

[IRIS.Islanding.1.9] The transient resulting from the design-basis grid islanding increase shall not cause any pressurizer safety valves to open.

[IRIS.Islanding.1.11] The transient resulting from the design-basis grid islanding increase shall not cause any steam line safety valves to open.

[IRIS.Islanding.1.12] The transient resulting from the design-basis grid islanding increase shall not cause any steam line relief valves to open.

[IRIS.Islanding.1.13] The transient resulting from the design-basis grid islanding increase shall not cause any turbine bypass valves to open.

[IRIS.Islanding.1.14] The transient resulting from the design-basis grid islanding increase shall not uncover the pressurizer heaters.

[IRIS.Islanding.1.15] The transient resulting from the design-basis grid islanding increase shall not cause high frequency rod stepping.

[IRIS.Islanding.1.16] The transient resulting from the design-basis grid islanding increase shall not cause any neutron flux signals used for automatic control or protection to exceed the value corresponding to $103 \%$ of licensed power. 
Exception: This requirement applies only to design analyses. It does not apply to plant startup tests.

[IRIS.Islanding.1.17] The transient resulting from the design-basis grid islanding increase shall not cause the steam superheat at the turbine inlet to drop below 25 Celsius degrees.

\subsubsection{GRID ISLANDING - DECREASE}

A grid disturbance outside the plant can separate the plant from the infinite grid, and lead to a change in the generator load. This section considers transients where the load decreases. In general, the load change occurs as a step. The magnitude of the change is not known in advance, and there is no practical way to measure it directly. Except for the most trivial load changes, the resulting mismatch between generation and load will result in a positive turbine/generator acceleration. The rate and magnitude of the acceleration depends on the size of the island and its load composition, especially the fraction of loads represented by rotating equipment. For load reductions of more than about 25 percent, grid disconnection on high frequency occurs within seconds. Most of the increase is due to steam that is already in the turbine when event occurs, so there is little that the control system can do to prevent the increase. Given the uncertainties, it is impractical to guarantee that the plant can survive islanding under all reasonable circumstances, so one must simply specify a design basis event. Testing a plant's ability to handle grid islanding is impractical, so the designers must rely on calculations.

The definition of the design-basis island mode decrease is as follows:

- The generator is initially delivering power at rated power factor to a finite grid with a grid load pickup factor of between (1) 1.17 to 3.5 percent load per Hertz for $60 \mathrm{~Hz}$ grids, or (2) 1.4 to 4.2 percent load per Hertz for 50 $\mathrm{Hz}$ grids.

- The load change appears as a step decrease in electrical load of no more than 20 percent.

- The initial plant electrical output is between 20 and 100 percent.

- The final grid power consumption is at least 20 percent at rated frequency.

- The grid islanding load decrease can occur at any time during the core cycle.

- The plant initial condition is quasi-steady state.

- All relevant process variables begin at their nominal values for the initial plant power.

- All relevant plant systems are operational and remain so.

- All relevant I\&C systems are in automatic control. 
The specific requirements defining acceptable responses to grid islanding load decreases (from a control and operations perspective) are as follows:

[IRIS.Islanding.2] The IRIS plant shall be able to perform the design-basis grid islanding load decrease.

[IRIS.Islanding.2.1] The transient resulting from the design-basis grid islanding load decrease shall bring the plant to a quasi-steady state condition without manual intervention.

[IRIS.Islanding.2.2] The transient resulting from the design-basis grid islanding load decrease shall not create diverging oscillations in any plant process variables (i.e. temperatures, pressures, flows, levels, etc.).

[IRIS.Islanding.2.3] The transient resulting from the design-basis grid islanding load decrease shall not cause a reactor trip.

[IRIS.Islanding.2.4] The transient resulting from the design-basis grid islanding load decrease shall not cause ESF actuation.

[IRIS.Islanding.2.5] The transient resulting from the design-basis grid islanding load decrease shall not cause a turbine trip.

[IRIS.Islanding.2.6] The transient resulting from the design-basis grid islanding load decrease shall not cause a turbine runback.

[IRIS.Islanding.2.7] The transient resulting from the design-basis grid islanding load decrease shall not cause a generator trip.

[IRIS.Islanding.2.8] The transient resulting from the design-basis grid islanding load decrease shall not cause a grid disconnect.

[IRIS.Islanding.2.9] The transient resulting from the design-basis grid islanding decrease shall not cause any pressurizer safety valves to open.

[IRIS.Islanding.2.10] The transient resulting from the design-basis grid islanding decrease shall not cause any steam line safety valves to open.

[IRIS.Islanding.2.11] The transient resulting from the design-basis grid islanding decrease shall not cause any steam line relief valves to open.

[IRIS.Islanding.2.12] The transient resulting from the design-basis grid islanding decrease shall not uncover the pressurizer heaters.

[IRIS.Islanding.2.13] The transient resulting from the design-basis grid islanding decrease shall not cause high frequency rod stepping.

[IRIS.Islanding.2.14] The transient resulting from the design-basis grid islanding decrease shall not cause any neutron flux signals used for automatic control or protection to exceed the value corresponding to $103 \%$ of licensed power.

Exception: This requirement applies only to design analyses. It does not apply to plant startup tests. 
[IRIS.Islanding.2.15] The transient resulting from the design-basis grid islanding decrease shall not cause the steam superheat at the turbine inlet to drop below 25 Celsius degrees.

[IRIS.Islanding.2.16] The transient resulting from the design-basis grid islanding decrease shall lead to frequency stabilizing in the range of (1) 59.5 to $60.5 \mathrm{~Hz}$ for $60-\mathrm{hz}$ grids, or (2) 49.5 to $50.5 \mathrm{~Hz}$. for $50-\mathrm{hz}$ grids.

\subsubsection{STEP LOAD REDUCTION TO HOUSE LOAD}

This event refers to opening any breaker that removes all off-site loads from the generator. This severs grid synchronization, so the turbine control system must revert to some form of speed control. Any plant loads receiving ac power from the generator will see changes in their supply frequency. The step load reduction to house load event differs from islanding (partial load rejection) event in two respects: first, monitoring the breaker position and generator MWe allows one to know the time, direction, and magnitude of the load change; and second, the grid frequency does not determine turbine speed. The step load reduction to house load event differs from the generator breaker trip event in assuming that house loads are connected to the generator. The house loads will probably be less than the minimum allowed turbine load, so the operator will probably trip the generator at some point.

The definition of the design-basis step load reduction to house load is as follows:

- A load change results from tripping the breakers tying the unit to the grid.

- A house load defined as $5 \%$ of rated power remains connected to the generator.

- The initial plant electrical output is greater than house load.

- The initial plant electrical output is no less than the minimum allowed steady-state turbine load.

- The initial plant electrical output is no more than $100 \%$.

- The step load reduction to house load can occur at any time during the core cycle.

- The plant initial condition is quasi-steady state.

- All relevant process variables begin at their nominal values for the initial plant power.

- All relevant plant systems are operational and remain so.

- All relevant I\&C systems are in automatic control. 
The specific requirements defining acceptable responses to step load reductions to house load (from a control and operations perspective) are as follows:

[IRIS.LoadRejection.1] The IRIS plant shall be able to perform the design-basis step load reduction to house load.

[IRIS.LoadRejection.1.1] The transient resulting from the design-basis step load reduction to house load shall bring the plant to a quasi-steady state condition without manual intervention.

[IRIS.LoadRejection.1.2] The transient resulting from the design-basis step load reduction to house load shall not create diverging oscillations in any plant process variables (i.e. temperatures, pressures, flows, levels, etc.).

[IRIS.LoadRejection. 1.3] The transient resulting from the design-basis step load reduction to house load shall not cause a reactor trip.

[IRIS.LoadRejection. 1.4] The transient resulting from the design-basis step load reduction to house load shall not cause ESF actuation.

[IRIS.LoadRejection. 1.5] The transient resulting from the design-basis step load reduction to house load shall not cause a turbine trip.

[IRIS.LoadRejection.1.6] The transient resulting from the design-basis step load reduction to house load shall not cause a generator trip.

[IRIS.LoadRejection. 1.7] The transient resulting from the design-basis step load reduction to house load shall not cause any pressurizer safety valves to open.

[IRIS.LoadRejection. 1.8] The transient resulting from the design-basis step load reduction to house load shall not cause any steam line safety valves to open.

[IRIS.LoadRejection. 1.9] The transient resulting from the design-basis step load reduction to house load shall not cause any steam line relief valves to open.

[IRIS.LoadRejection.1.10] The transient resulting from the design-basis step load reduction to house load shall not cause any turbine bypass valves to remain open in the final quasi-steady-state.

Exception: If decay heat exceeds the thermal power necessary to maintain house load, then the turbine bypass valves may remain open to relieve the difference.

[IRIS.LoadRejection.1.11] The transient resulting from the design-basis step load reduction to house load shall not uncover the pressurizer heaters.

[IRIS.LoadRejection.1.12] The transient resulting from the design-basis step load reduction to house load shall not cause high frequency rod stepping. 
[IRIS.LoadRejection.1.13] The transient resulting from the design-basis step load reduction to house load shall not cause any neutron flux signals used for automatic control or protection to exceed the value corresponding to $103 \%$ of licensed power.

Exception: This requirement applies only to design analyses. It does not apply to plant startup tests.

[IRIS.LoadRejection.1.14] The transient resulting from the design-basis step load reduction to house load shall not cause the steam superheat at the turbine inlet to drop below 25 Celsius degrees.

[IRIS.LoadRejection.1.15] The transient resulting from the design-basis step load reduction to house load shall lead to frequency stabilizing in the range of (1) 59.5 to $60.5 \mathrm{~Hz}$ for 60-hz grids, or (2) 49.5 to $50.5 \mathrm{~Hz}$. for 50 -hz grids.

\subsubsection{TURBINE FAST VALVING}

Turbine fast valving is a technique used to enhance grid stability by allowing the generator to maintain synchronization under certain grid fault (short circuit) conditions. In particular, fast valving reduces the turbine powergenerator power mismatch so that the electrical system has more time to clear the fault. The electrical system initiates fast valving; the operator cannot do so. Fast valving is normally blocked except at high power. A typical fast valving event closes the turbine throttle valves at maximum speed, holds them closed for a few seconds, and then opens them at a rapid (yet not maximum) rate until turbine load returns to nearly its original value. It is impractical to design a system that can withstand all grid faults without tripping the unit on electrical conditions. For IRIS, we require that the turbine and reactor systems be able to handle the transient if the electrical system does.

The definition of the design-basis turbine fast valving event is as follows:

- The initiating event is a three-phase short circuit. For non-electrical design purposes, assume that the short circuit occurs at the generator terminals.

- The electrical system clears the fault before the generator acceleration violates the equal angle criteria. For non-electrical design purposes, assume that the generator remains synchronized.

- The initial plant electrical output is at least 80 percent power and at rated power factor.

- The maximum transmittable power following the event is between 70 and 100 percent of the transmittable power before the event.

- The remaining connected tie line capacity following the event is at least 60 percent of rated plant output. 
- The final grid power consumption does not exceed 100 percent at rated frequency.

- The short circuit can occur at any time during the core cycle.

- The plant initial condition is quasi-steady state.

- All relevant process variables begin at their nominal values for the initial plant power.

- All relevant plant systems are operational and remain so.

- All relevant I\&C systems are in automatic control.

The specific requirements defining acceptable responses to turbine fast valving events (from a control and operations perspective) are as follows:

[IRIS.FastValving.1] The IRIS plant shall be able to perform the design-basis turbine fast valving.

[IRIS.FastValving.1.1] The transient resulting from the design-basis turbine fast valving shall bring the plant to a quasi-steady state condition without manual intervention.

[IRIS.FastValving. 1.2] The transient resulting from the design-basis turbine fast valving shall not create diverging oscillations in any plant process variables (i.e. temperatures, pressures, flows, levels, etc.).

[IRIS.FastValving.1.3] The transient resulting from the design-basis turbine fast valving shall not cause a reactor trip.

[IRIS.FastValving. 1.4] The transient resulting from the design-basis turbine fast valving shall not cause ESF actuation.

[IRIS.FastValving.1.5] The transient resulting from the design-basis turbine fast valving shall not cause a turbine trip.

[IRIS.FastValving.1.6] The transient resulting from the design-basis turbine fast valving shall not cause a turbine runback.

Exception: The design may use a turbine runback to bring the final plant power output down to the remaining connected tie line capacity with a $(+0 \%,-5 \%)$ tolerance on the setting.

[IRIS.FastValving.1.7] The transient resulting from the design-basis turbine fast valving shall not cause a generator trip.

Exception: A generator trip may occur if required to clear the short. If this occurs, consider this to be a generator trip event and apply the corresponding acceptance criteria.

[IRIS.FastValving. 1.8] The frequency transient resulting from the designbasis turbine fast valving shall not cause a grid disconnect.

Exception: Grid disconnect may occur if required to clear the short. If this occurs, consider this to be a step load reduction to 
house load event and apply the corresponding acceptance criteria.

[IRIS.FastValving.1.9] The transient resulting from the design-basis turbine fast valving shall not cause any pressurizer safety valves to open.

[IRIS.FastValving.1.10] The transient resulting from the design-basis turbine fast valving shall not cause any steam line safety valves to open.

[IRIS.FastValving.1.11] The transient resulting from the design-basis turbine fast valving shall not cause any steam line relief valves to open.

[IRIS.FastValving.1.12] The transient resulting from the design-basis turbine fast valving shall not uncover the pressurizer heaters.

[IRIS.FastValving.1.13] The transient resulting from the design-basis turbine fast valving shall not cause high frequency rod stepping.

[IRIS.FastValving.1.14] The transient resulting from the design-basis turbine fast valving shall not cause the steam superheat at the turbine inlet to drop below 25 Celsius degrees.

\subsubsection{REACTOR, TURBINE, AND GENERATOR TRIPS}

\subsubsection{NORMAL REACTOR TRIP}

A reactor trip results in reactor shutdown. Upon detecting a reactor trip, the turbine protection system trips the turbine soon after. Rod control and turbine throttle valve control no longer operate, but most other reactor control functions continue in one form or another. This section considers a reactor trip from an I\&C operations point-of-view rather than an accident analysis point-ofview. Proper control system operation reduces the severity of the transient that follows a reactor trip; however, the accident analyses cannot credit the beneficial aspects of proper control system operation. The requirements presented here take such credit, so the initiating event and corresponding acceptance criteria presented here are different from those assumed in the accident analyses.

The definition of the design-basis normal reactor trip is as follows:

- The initiating event is a manual reactor trip command.

- The normal reactor trip can occur at any time during the core cycle.

- The plant initial condition is quasi-steady state.

- All relevant process variables begin at their nominal values for the initial plant power.

- All relevant plant systems are operational and remain so.

- All relevant I\&C systems are in automatic control. 
The specific requirements defining acceptable responses to normal reactor trips (from a control and operations perspective) are as follows:

[IRIS.ReactorTrip.1] The IRIS plant shall be able to perform the design-basis normal reactor trip.

[IRIS.ReactorTrip.1.1] The transient resulting from the design-basis normal reactor trip shall bring the plant to a quasi-steady state condition without manual intervention.

[IRIS.ReactorTrip.1.2] The transient resulting from the design-basis normal reactor trip shall not create diverging oscillations in any plant process variables (i.e., temperatures, pressures, flows, levels, etc.).

[IRIS.ReactorTrip.1.3] The transient resulting from the design-basis normal reactor trip shall not cause ESF actuation.

[IRIS.ReactorTrip.1.4] The transient resulting from the design-basis normal reactor trip shall include a turbine trip.

[IRIS.ReactorTrip.1.5] The transient resulting from the design-basis normal reactor trip shall not cause a grid disconnect.

[IRIS.ReactorTrip.1.6] The transient resulting from the design-basis normal reactor trip shall not cause any pressurizer safety valves to open.

[IRIS.ReactorTrip.1.7] The transient resulting from the design-basis normal reactor trip shall not cause any steam line safety valves to open.

[IRIS.ReactorTrip.1.8] The transient resulting from the design-basis normal reactor trip shall not cause any steam line relief valves to open.

[IRIS.ReactorTrip.1.9] The transient resulting from the design-basis normal reactor trip shall stabilize with the turbine bypass valves stabilized at the position needed to remove decay heat.

[IRIS.ReactorTrip.1.10] The transient resulting from the design-basis normal reactor trip shall not cause uncovering of the pressurizer heaters.

\subsubsection{NORMAL TURBINE TRIP}

A turbine trip introduces a sudden and complete termination of the principal thermal load on the NSSS, leading to the most severe anticipated transient not involving a reactor trip. IRIS must handle a turbine trip at full power without reactor trip. Turbine throttle valve control no longer operates after the trip, but most reactor control functions continue in one form or another. This section considers a turbine trip from an I\&C operations point-of-view rather than an accident analysis point-of-view. Proper control system operation reduces the severity of the transient that follows a turbine trip; however, the accident analyses cannot credit the beneficial aspects of proper control system operation. The requirements presented here take such credit, so the initiating 
event and corresponding acceptance criteria are different from those assumed in the accident analyses.

The definition of the design-basis normal turbine trip is as follows:

- The initiating event is a manual turbine trip command.

- The normal turbine trip can occur at any time during the core cycle.

- The plant initial condition is quasi-steady state.

- All relevant process variables begin at their nominal values for the initial plant power.

- All relevant plant systems are operational and remain so.

- All relevant I\&C systems are in automatic control.

The specific requirements defining acceptable responses to normal turbine trips (from a control and operations perspective) are as follows:

[IRIS.TurbineTrip.1] The IRIS plant shall be able to perform the design-basis normal turbine trip.

[IRIS.TurbineTrip.1.1] The transient resulting from the design-basis normal turbine trip shall bring the plant to a quasi-steady state condition without manual intervention.

[IRIS.TurbineTrip.1.2] The transient resulting from the design-basis normal turbine trip shall not create diverging oscillations in any plant process variables (i.e., temperatures, pressures, flows, levels, etc.).

[IRIS.TurbineTrip.1.3] The transient resulting from the design-basis normal turbine trip shall not cause a reactor trip.

[IRIS.TurbineTrip.1.4] The transient resulting from the design-basis normal turbine trip shall not cause ESF actuation.

[IRIS.TurbineTrip.1.5] The transient resulting from the design-basis normal turbine trip shall not cause a grid disconnect.

[IRIS.TurbineTrip.1.6] The transient resulting from the design-basis normal turbine trip shall not cause any pressurizer safety valves to open.

[IRIS.TurbineTrip.1.7] The transient resulting from the design-basis normal turbine trip shall not cause any steam line safety valves to open.

[IRIS.TurbineTrip.1.8] The transient resulting from the design-basis normal turbine trip shall not cause any steam line relief valves to open.

[IRIS.TurbineTrip.1.9] The transient resulting from the design-basis turbine trip shall stabilize with the turbine bypass valves stabilized at the position needed to remove decay heat.

[IRIS.TurbineTrip.1.10] The transient resulting from the design-basis normal turbine trip shall not uncover the pressurizer heaters. 
[IRIS.TurbineTrip.1.11] The transient resulting from the design-basis turbine trip shall not cause high frequency rod stepping.

[IRIS.TurbineTrip.1.12] The transient resulting from the design-basis turbine trip shall not cause any neutron flux signals used for automatic control or protection to exceed the value corresponding to $103 \%$ of licensed power.

Exception: This requirement applies only to design analyses. It does not apply to plant startup tests.

\subsubsection{NORMAL GENERATOR TRIP}

Opening the generator breaker removes all electrical loads from the generator. This severs generator-to-grid synchronization, so the turbine control system must revert to some form of speed control. This event differs from the step load reduction to house load event in that house loads are disconnected from the generator. The grid remains available as an electrical power source, and grid frequency remains, for all practical purposes, at its nominal value.

The definition of the design-basis normal generator trip is as follows:

- The load change results from tripping the generator output breaker.

- The generator trip can occur at any time during the core cycle.

- Relevant plant electrical loads are transferred to (or remain connected to) the grid and subsequently receive power at nominal grid frequency.

- The plant initial condition is quasi-steady state.

- All relevant process variables begin at their nominal values for the initial plant power.

- All relevant plant systems are operational and remain so.

- All relevant I\&C systems are in automatic control.

- The initial plant electrical output is no more than $100 \%$.

The specific requirements defining acceptable responses to normal generator trips (from a control and operations perspective) are as follows:

[IRIS.GeneratorTrip.1] The IRIS plant shall be able to perform the design-basis normal generator trip.

[IRIS.GeneratorTrip.1.1] The transient resulting from the design-basis normal generator trip shall bring the plant to a quasi-steady state condition without manual intervention.

[IRIS.GeneratorTrip.1.2] The transient resulting from the design-basis normal generator trip shall not create diverging oscillations in any plant process variables (i.e., temperatures, pressures, flows, levels, etc.). 
[IRIS.GeneratorTrip.1.3] The transient resulting from the design-basis normal generator trip shall not cause a reactor trip.

[IRIS.GeneratorTrip.1.4] The transient resulting from the design-basis normal generator trip shall not cause ESF actuation.

[IRIS.GeneratorTrip.1.5] The transient resulting from the design-basis normal generator trip shall not cause a turbine trip.

[IRIS.GeneratorTrip.1.6] The transient resulting from the design-basis normal generator trip shall not cause a grid disconnect.

[IRIS.GeneratorTrip.1.7] The transient resulting from the design-basis normal generator trip shall not cause any pressurizer safety valves to open.

[IRIS.GeneratorTrip.1.8] The transient resulting from the design-basis normal generator trip shall not cause any steam line safety valves to open.

[IRIS.GeneratorTrip.1.9] The transient resulting from the design-basis normal generator trip shall not cause any steam line relief valves to open.

[IRIS.GeneratorTrip.1.10] The transient resulting from the design-basis normal generator trip shall shall not cause any turbine bypass valves to remain open in the final quasi-steady-state.

[IRIS.GeneratorTrip.1.11] The transient resulting from the design-basis normal generator trip shall not uncover the pressurizer heaters.

[IRIS.GeneratorTrip.1.12] The transient resulting from the design-basis normal generator trip shall not cause high frequency rod stepping.

[IRIS.GeneratorTrip.1.13] The transient resulting from the design-basis normal generator trip shall not cause any neutron flux signals used for automatic control or protection to exceed the value corresponding to $103 \%$ of licensed power.

Exception: This requirement applies only to design analyses. It does not apply to plant startup tests.

\subsubsection{LOSS OF MAJOR PLANT COMPONENTS}

\subsubsection{LOSS OFA RUNNING MAIN REACTOR COOLANT PUMP}

The appropriate plant response to tripping a main reactor coolant pump depends on the initial power and the number of pumps in service. IRIS operates with eight main reactor coolant pumps in service at full power. Since the steam generators are connected in pairs, tripping one main reactor coolant pump requires tripping the one associated with the paired steam generator. 
The definition of the design-basis loss of a running main reactor coolant pump is as follows:

- The loss of a running main reactor coolant pump is equivalent to manually tripping the affected pump (i.e., it is not due to causes external to the pump).

- The loss of a running main reactor coolant pump can occur at any time during the core cycle.

- The plant initial condition is quasi-steady state.

- The number of operating main reactor coolant pumps is the full compliment normally operating at full power.

- All relevant process variables begin at their nominal values for the initial plant power.

- All relevant plant systems are operational and remain so.

- All relevant I\&C systems are in automatic control.

The specific requirements defining acceptable responses to loss of a running main reactor coolant pump (from a control and operations perspective) are as follows:

[IRIS.RCPTrip.1] The IRIS plant shall be able to perform the design-basis loss of a running main reactor coolant pump.

[IRIS.RCPTrip.1.1] The transient resulting from the design-basis loss of a running main reactor coolant pump shall bring the plant to a quasisteady state condition without manual intervention.

[IRIS.RCPTrip.1.2] The transient resulting from the design-basis loss of a running main reactor coolant pump shall not create diverging oscillations in any plant process variables (i.e., temperatures, pressures, flows, levels, etc.).

[IRIS.RCPTrip.1.3] The transient resulting from the design-basis loss of a running main reactor coolant pump shall not cause a reactor trip.

[IRIS.RCPTrip. 1.4] The transient resulting from the design-basis loss of a running main reactor coolant pump shall not cause ESF actuation.

[IRIS.RCPTrip.1.5] The transient resulting from the design-basis loss of a running main reactor coolant pump shall not cause a turbine trip.

[IRIS.RCPTrip.1.6] The transient resulting from the design-basis loss of a running main reactor coolant pump shall not cause a generator trip.

[IRIS.RCPTrip.1.7] The transient resulting from the design-basis loss of a running main reactor coolant pump shall not cause a grid disconnect. 
[IRIS.RCPTrip.1.8] The transient resulting from the design-basis loss of a running main reactor coolant pump shall not cause any pressurizer safety valves to open.

[IRIS.RCPTrip.1.9] The transient resulting from the design-basis loss of a running main reactor coolant pump shall not cause any steam line safety valves to open.

[IRIS.RCPTrip.1.10] The transient resulting from the design-basis loss of a running main reactor coolant pump shall not cause any steam line relief valves to open.

[IRIS.RCPTrip.1.11] The transient resulting from the design-basis loss of a running main reactor coolant pump shall not cause any turbine bypass valves to remain open in the final quasi-steady-state.

[IRIS.RCPTrip.1.12] The transient resulting from the design-basis loss of a running main reactor coolant pump uncover the pressurizer heaters.

[IRIS.RCPTrip.1.13] The transient resulting from the design-basis loss of a running main reactor coolant pump shall not cause high frequency rod stepping.

[IRIS.RCPTrip.1.14] The transient resulting from the design-basis loss of a running main reactor coolant pump shall not cause the steam superheat at the turbine inlet to drop below 25 Celsius degrees.

[IRIS.RCPTrip.1.14] The design-basis loss of a running main reactor coolant pump shall result in tripping the main reactor coolant pump associated with the paired steam generator.

\subsubsection{LOSS OFA RUNNING MAIN FEEDWATER PUMP}

The appropriate plant response to tripping a feedwater pump depends on the initial power and the number of pumps in service. IRIS operates with two feedwater pumps in service at full power.

The definition of the design-basis loss of a running main feedwater pump is as follows:

- The loss of a running main feedwater pump is equivalent to manually tripping the affected pump (i.e., it is not due to causes external to the pump).

- The loss of a running main feedwater pump can occur at any time during the core cycle.

- The plant initial condition is quasi-steady state.

- The number of operating feedwater pumps is the full compliment normally operating at full power. 
- All relevant process variables begin at their nominal values for the initial plant power.

- All relevant plant systems are operational and remain so.

- All relevant I\&C systems are in automatic control.

The specific requirements defining acceptable responses to loss of a running main feedwater pump (from a control and operations perspective) are as follows:

[IRIS.FWPumpTrip.1] The IRIS plant shall be able to perform the design-basis loss of a running main feedwater pump.

[IRIS.FWPumpTrip.1.1] The transient resulting from the design-basis loss of a running main feedwater pump shall bring the plant to a quasi-steady state condition without manual intervention.

[IRIS.FWPumpTrip.1.2] The transient resulting from the design-basis loss of a running main feedwater pump shall not create diverging oscillations in any plant process variables (i.e., temperatures, pressures, flows, levels, etc.).

[IRIS.FWPumpTrip.1.3] The transient resulting from the design-basis loss of a running main feedwater pump shall not cause a reactor trip.

[IRIS.FWPumpTrip.1.4] The transient resulting from the design-basis loss of a running main feedwater pump shall not cause ESF actuation.

[IRIS.FWPumpTrip.1.5] The transient resulting from the design-basis loss of a running main feedwater pump shall not cause a turbine trip.

[IRIS.FWPumpTrip.1.6] The transient resulting from the design-basis loss of a running main feedwater pump shall not cause a generator trip.

[IRIS.FWPumpTrip.1.7] The transient resulting from the design-basis loss of a running main feedwater pump shall not cause a grid disconnect.

[IRIS.FWPumpTrip.1.8] The transient resulting from the design-basis loss of a running main feedwater pump shall not cause any pressurizer safety valves to open.

[IRIS.FWPumpTrip.1.9] The transient resulting from the design-basis loss of a running main feedwater pump shall not cause any steam line safety valves to open.

[IRIS.FWPumpTrip.1.10] The transient resulting from the design-basis loss of a running main feedwater pump shall not cause any steam line relief valves to open.

[IRIS.FWPumpTrip.1.11] The transient resulting from the design-basis loss of a running main feedwater pump shall not cause any turbine bypass valves to remain open in the final quasi-steady-state. 
[IRIS.FWPumpTrip.1.12] The transient resulting from the design-basis loss of a running main feedwater pump shall not uncover the pressurizer heaters.

[IRIS.FWPumpTrip.1.13] The transient resulting from the design-basis loss of a running main feedwater pump shall not cause high frequency rod stepping.

[IRIS.FWPumpTrip.1.14] The transient resulting from the design-basis loss of a running main feedwater pump shall not cause the steam superheat at the turbine inlet to drop below 25 Celsius degrees.

\subsubsection{LOSS OFA RUNNING CONDENSATE PUMP}

The appropriate plant response to tripping a condensate pump depends on the initial power and the number of pumps in service. IRIS has three condensate pumps and operates with two pumps in service at full power. The third pump can start automatically if one of the operating pumps trips.

The definition of the design-basis loss of a running condensate pump is as follows:

- The loss of a running condensate pump is equivalent to manually tripping the affected pump (i.e., it is not due to causes external to the pump).

- The loss of a running condensate pump can occur at any time during the core cycle.

- The plant initial condition is quasi-steady state.

- The number of operating condensate pumps is the full complement normally operating at full power.

- All relevant process variables begin at their nominal values for the initial plant power.

- All relevant plant systems are operational and remain so.

- All relevant I\&C systems are in automatic control.

The specific requirements defining acceptable responses to loss of a running condensate pump (from a control and operations perspective) are as follows:

[IRIS.CondensatePumpTrip.1] The IRIS plant shall be able to perform the design-basis loss of a running condensate pump.

[IRIS.CondensatePumpTrip.1.1] The transient resulting from the designbasis loss of a running condensate pump shall bring the plant to a quasi-steady state condition without manual intervention.

[IRIS.CondensatePumpTrip.1.2] The transient resulting from the designbasis loss of a running condensate pump shall not create diverging 
oscillations in any plant process variables (i.e., temperatures, pressures, flows, levels, etc.).

[IRIS.CondensatePumpTrip.1.3] The transient resulting from the designbasis loss of a running condensate pump shall not cause a reactor trip.

[IRIS.CondensatePumpTrip.1.4] The transient resulting from the designbasis loss of a running condensate pump shall not cause ESF actuation.

[IRIS.CondensatePumpTrip.1.5] The transient resulting from the designbasis loss of a running condensate pump shall not cause a turbine trip.

[IRIS.CondensatePumpTrip.1.6] The transient resulting from the designbasis loss of a running condensate pump shall not cause a turbine runback.

[IRIS.CondensatePumpTrip.1.7] The transient resulting from the designbasis loss of a running condensate pump shall not cause a generator trip.

[IRIS.CondensatePumpTrip.1.8] The transient resulting from the designbasis loss of a running condensate pump shall not cause a grid disconnect.

[IRIS.CondensatePumpTrip.1.9] The transient resulting from the designbasis loss of a running condensate pump shall not cause a feedwater pump trip.

[IRIS.CondensatePumpTrip.1.10] The transient resulting from the designbasis loss of a running condensate pump shall not cause any pressurizer safety valves to open.

[IRIS.CondensatePumpTrip.1.11] The transient resulting from the designbasis loss of a running condensate pump shall not cause any steam line safety valves to open.

[IRIS.CondensatePumpTrip.1.12] The transient resulting from the designbasis loss of a running condensate pump shall not cause any steam line relief valves to open.

[IRIS.CondensatePumpTrip.1.13] The transient resulting from the designbasis loss of a running condensate pump shall not cause any turbine bypass valves to open.

[IRIS.CondensatePumpTrip.1.14] The transient resulting from the designbasis loss of a running condensate pump shall not uncover the pressurizer heaters.

[IRIS.CondensatePumpTrip.1.15] The transient resulting from the designbasis loss of a running condensate pump shall not cause high frequency rod stepping. 
[IRIS.CondensatePumpTrip.1.16] The transient resulting from the designbasis loss of a running condensate pump shall not cause the steam superheat at the turbine inlet to drop below 25 Celsius degrees.

\subsubsection{INADVERTENT FEEDWATER VALVE CLOSURE}

Feedwater valve failures involve inadvertent opening or closing of a feedwater valve. The appropriate plant response to inadvertent feedwater valve closure is to reduce power. The IRIS plant should be able to handle this event while remaining on line.

The definition of the design-basis inadvertent feedwater valve closure is as follows:

- The inadvertent feedwater valve closure is equivalent to a step reduction in feedwater flow to the affected steam generators, neglecting momentum effects (e.g., no water hammer opr acoustic wave phenomena).

- The inadvertent feedwater valve closure can occur at any time during the core cycle.

- The plant initial condition is quasi-steady state.

- The number of operating feedwater valves is the full compliment normally operating at full power.

- All relevant process variables begin at their nominal values for the initial plant power.

- All relevant plant systems are operational and remain so.

- All relevant I\&C systems are in automatic control.

The specific requirements defining acceptable responses to an inadvertent feedwater valve closure (from a control and operations perspective) are as follows:

[IRIS.FWValveClosure.1] The IRIS plant shall be able to perform the designbasis inadvertent feedwater valve closure.

[IRIS.FWValveClosure.1.1] The transient resulting from the design-basis inadvertent feedwater valve closure shall bring the plant to a quasisteady state condition without manual intervention.

[IRIS.FWValveClosure.1.2] The transient resulting from the design-basis inadvertent feedwater valve closure shall not create diverging oscillations in any plant process variables (i.e., temperatures, pressures, flows, levels, etc.).

[IRIS.FWValveClosure.1.3] The transient resulting from the design-basis inadvertent feedwater valve closure shall not cause a reactor trip.

[IRIS.FWValveClosure.1.4] The transient resulting from the design-basis inadvertent feedwater valve closure shall not cause ESF actuation. 
[IRIS.FWValveClosure.1.5] The transient resulting from the design-basis inadvertent feedwater valve closure shall not cause a turbine trip.

[IRIS.FWValveClosure.1.6] The transient resulting from the design-basis inadvertent feedwater valve closure shall not cause a generator trip.

[IRIS.FWValveClosure.1.7] The transient resulting from the design-basis inadvertent feedwater valve closure shall not cause a grid disconnect.

[IRIS.FWValveClosure.1.8] The transient resulting from the design-basis inadvertent feedwater valve closure shall not cause any pressurizer safety valves to open.

[IRIS.FWValveClosure.1.9] The transient resulting from the design-basis inadvertent feedwater valve closure shall not cause any steam line safety valves to open.

[IRIS.FWValveClosure.1.10] The transient resulting from the design-basis inadvertent feedwater valve closure shall not cause any steam line relief valves to open.

[IRIS.FWValveClosure.1.11] The transient resulting from the design-basis inadvertent feedwater valve closure shall not uncover the pressurizer heaters.

[IRIS.FWValveClosure.1.12] The transient resulting from the design-basis inadvertent feedwater valve closure shall not cause high frequency rod stepping.

[IRIS.FWValveClosure.1.13] The transient resulting from the design-basis inadvertent feedwater valve closure shall not cause the steam superheat at the turbine inlet to drop below 25 Celsius degrees.

\subsubsection{LOSS OF A FEEDWATER HEATER}

According to preliminary information, an IRIS unit will have two low-pressure feedwater heater trains, a deaerating feedwater heater, and one pair of highpressure feedwater heaters

Controlled removal of one or more groups of feedwater heaters does not result in significant plant transients requiring automatic control action. The loss of a feedwater heater event refers to the uncontrolled loss of feedwater heating resulting from the inadvertent closing of one of the extraction steam supply valves.

The definition of the design-basis loss of a feedwater heater is as follows:

- The loss of a feedwater heater results from closing the extraction steam supply.

- The tube-side flow path through the heaters remains open.

- The plant initial condition is quasi-steady state. 
- The number of operating feedwater heaters is the full complement normally operating at power.

- All relevant process variables begin at their nominal values for the initial plant power.

- All relevant plant systems are operational and remain so.

- All relevant I\&C systems are in automatic control.

The specific requirements defining acceptable responses to loss of a feedwater heater (from a control and operations perspective) are as follows:

[IRIS.FWHeaterLoss.1] The IRIS plant shall be able to perform the design-basis loss of a feedwater heater.

[IRIS.FWHeaterLoss.1.1] The transient resulting from the design-basis loss of a feedwater heater shall bring the plant to a quasi-steady state condition without manual intervention.

[IRIS.FWHeaterLoss.1.2] The transient resulting from the design-basis loss of a feedwater heater shall not create diverging oscillations in any plant process variables (i.e., temperatures, pressures, flows, levels, etc.).

[IRIS.FWHeaterLoss.1.3] The transient resulting from the design-basis loss of a feedwater heater shall not cause a reactor trip.

[IRIS.FWHeaterLoss.1.4] The transient resulting from the design-basis loss of a feedwater heater shall not cause ESF actuation.

[IRIS.FWHeaterLoss.1.5] The transient resulting from the design-basis loss of a feedwater heater shall not cause a turbine trip.

[IRIS.FWHeaterLoss.1.6] The transient resulting from the design-basis loss of a feedwater heater shall not cause a generator trip.

[IRIS.FWHeaterLoss.1.7] The transient resulting from the design-basis loss of a feedwater heater shall not cause a grid disconnect.

[IRIS.FWHeaterLoss.1.8] The transient resulting from the design-basis loss of a feedwater heater shall not cause any pressurizer safety valves to open.

[IRIS.FWHeaterLoss.1.9] The transient resulting from the design-basis loss of a feedwater heater shall not cause any steam line safety valves to open.

[IRIS.FWHeaterLoss.1.10] The transient resulting from the design-basis loss of a feedwater heater shall not cause any steam line relief valves to open.

[IRIS.FWHeaterLoss.1.11] The transient resulting from the design-basis loss of a feedwater heater shall not cause any turbine bypass valves to open. 
[IRIS.FWHeaterLoss.1.12] The transient resulting from the design-basis loss of a feedwater heater shall not uncover the pressurizer heaters.

[IRIS.FWHeaterLoss.1.13] The transient resulting from the design-basis loss of a feedwater heater shall not cause high frequency rod stepping.

[IRIS.FWHeaterLoss.1.14] The transient resulting from the design-basis loss of a feedwater heater shall not cause any neutron flux signals used for automatic control or protection to exceed the value corresponding to $103 \%$ of licensed power.

Exception: This requirement applies only to design analyses. It does not apply to plant startup tests.

[IRIS.FWHeaterLoss.1.15] The transient resulting from the design-basis loss of a feedwater heater shall not cause the steam superheat at the turbine inlet to drop below 25 Celsius degrees.

\subsubsection{MISCELLANEOUS UPSETS}

\subsubsection{UNINTENDED CONTROL ROD DROP}

IRIS should be designed to accommodate the following events associated with an unintended control rod drop.

- No scram upon dropping a control rod

- Operation at reduced power for four hours with any single control rod drive fully inserted;

- Recover rod without initiating a scram or exceeding fuel design limits.

This addresses a limitation of most earlier PWRs in which a rod drop automatically initiates a reactor scram or the technical specifications require that the plant be at cold shutdown within a short time. Providing the capability for continued operation, despite an unintended single rod drop, will improve the plant capacity factor and reduce the wear associated with a shutdown and startup cycle. The first bullet, "no scram upon dropping a control rod," is the only one directly addressed by the I\&C System.

The definition of the design-basis unintended control rod drop is as follows:

- A single control rod drops due to malfunctions whose sole direct effect is to initiate the single control rod drop.

- The initial plant electrical output does not exceed $100 \%$.

- The unintended control rod drop can occur at any time during the core cycle.

- The plant initial condition is quasi-steady state. 
- All relevant process variables begin at their nominal values for the initial plant power.

- All relevant plant systems are operational and remain so.

- All relevant I\&C systems other than the reactor control rods are in automatic control. The reactor control rods may be in automatic or manual.

The specific requirements defining acceptable responses to an unintended control rod drop (from a control and operations perspective) are as follows:

[IRIS.RodDrop.1] The IRIS plant shall be able to perform the design-basis unintended control rod drop.

[IRIS.RodDrop.1.1] The transient resulting from the design-basis unintended control rod drop shall bring the plant to a quasi-steady state condition without manual intervention.

Exception: The operator will recover the control rod manually.

[IRIS.RodDrop.1.2] The transient resulting from the design-basis unintended control rod drop shall not create diverging oscillations in any plant process variables (i.e., temperatures, pressures, flows, levels, etc.).

[IRIS.RodDrop.1.3] The transient resulting from the design-basis unintended control rod drop shall not cause a reactor trip.

[IRIS.RodDrop.1.4] The transient resulting from the design-basis unintended control rod drop shall not cause ESF actuation.

[IRIS.RodDrop. 1.5] The transient resulting from the design-basis unintended control rod drop shall not cause a turbine trip.

[IRIS.RodDrop.1.6] The transient resulting from the design-basis unintended control rod drop shall not cause a generator trip.

[IRIS.RodDrop.1.7] The transient resulting from the design-basis unintended control rod drop shall not cause a grid disconnect.

[IRIS.RodDrop.1.8] The transient resulting from the design-basis unintended control rod drop shall not cause any pressurizer safety valves to open.

[IRIS.RodDrop.1.9] The transient resulting from the design-basis unintended control rod drop shall not cause any steam line safety valves to open.

[IRIS.RodDrop.1.10] The transient resulting from the design-basis unintended control rod drop shall not cause any steam line relief valves to open.

[IRIS.RodDrop.1.11] The transient resulting from the design-basis unintended control rod drop shall stabilize with the turbine bypass valves closed. 
[IRIS.RodDrop.1.12] The transient resulting from the design-basis unintended control rod drop shall not uncover the pressurizer heaters.

[IRIS.RodDrop.1.13] The transient resulting from the design-basis unintended control rod drop shall not cause high frequency rod stepping.

[IRIS.RodDrop.1.14] The transient resulting from the design-basis unintended control rod drop shall not cause any neutron flux signals used for automatic control or protection to exceed the value corresponding to $103 \%$ of licensed power.

Exception: This requirement applies only to design analyses. It does not apply to plant startup tests.

[IRIS.RodDrop.1.15] The transient resulting from the design-basis unintended control rod drop shall not cause the steam superheat at the turbine inlet to drop below 25 Celsius degrees.

\subsection{REFERENCE EVENTS}

The events listed in this section traditionally are used for PWR design purposes. They are artificial transients intended only for control system performance evaluation. They do not necessarily represent realistic events for any electric power generating station. We wrote these acceptance criteria for control and protection system analysis only. None of these events or their acceptance criteria belongs as part of the initial plant startup tests.

\subsubsection{STEP LOAD INCREASE}

The 10 percent step load increase transient traditionally used for PWR design purposes is an artificial transient intended only for control system performance evaluation. It does not represent a realistic transient for an electric power generating station. In practice, there can only be two ways to initiate such a transient:

- Have the operator initiate the transient: One would be hard-pressed to suggest a scenario where such a large load change would be required and the precise magnitude and timing known in advance. Expected load changes can invariably be accommodated by slower ramp load changes. Many plants do not allow the operator to request step load changes; instead, they restrict the operator's actions to limit load changes to the design ramp rate.

- Have the plant respond to sudden grid load changes: A grid disturbance outside the plant can separate the plant from the infinite grid, and lead to a change in the generator load. The only mechanism available for detecting sudden grid load changes is the sudden change in grid frequency. By convention, these are "islanding events." 
Although step load changes are not realistic transients, designers analyze them for several reasons. First, and most important, they are among the best transients for evaluating control system performance characteristics such as overshoot, damping ratio, and settling time. Second, and of less importance, step load changes generally result in larger excursions from nominal plant conditions than the ramp load changes do, so they are useful indicators of worse-case bounds on the margins to certain reactor trip set points and other plant limits. Normal analysis practice requires that the starting and ending powers lie within the normal maneuvering range and that the initial conditions are nominal conditions with perhaps some deliberate bias for conservatism.

The definition of the design-basis step load increase is as follows:

- A load change results from an operator request to the supervisory control system.

- The load change request is for an instantaneous increase in demanded power generation of up to 10 percent of guaranteed electrical output.

- The initial plant electrical output is at least 20 percent.

- The final demanded output does not exceed $100 \%$.

- The step load increase can occur at any time during the core cycle.

- The plant initial condition is quasi-steady state.

- All relevant process variables begin at their nominal values for the initial plant power.

- All relevant plant systems are operational and remain so.

- All relevant I\&C systems are in automatic control.

- The initial control rod position provides for adequate rod withdrawal during the resulting transient.

The specific requirements defining acceptable responses to step load increases (from a control and operations perspective) are as follows:

[IRIS.StepChange.1] The IRIS plant shall be able to perform the design-basis step load increase.

[IRIS.StepChange.1.1] The transient resulting from the design-basis step load increase shall bring the plant to a quasi-steady state condition without manual intervention.

[IRIS.StepChange.1.2] The transient resulting from the design-basis step load increase shall not create diverging oscillations in any plant process variables (i.e. temperatures, pressures, flows, levels, etc.).

[IRIS.StepChange.1.3] The transient resulting from the design-basis step load increase shall not cause a reactor trip. 
[IRIS.StepChange.1.4] The transient resulting from the design-basis step load increase shall not cause ESF actuation.

[IRIS.StepChange.1.5] The transient resulting from the design-basis step load increase shall not cause a turbine trip.

[IRIS.StepChange.1.6] The transient resulting from the design-basis step load increase shall not cause a turbine runback.

[IRIS.StepChange.1.7] The transient resulting from the design-basis step load increase shall not cause a generator trip.

[IRIS.StepChange.1.8] The transient resulting from the design-basis step load increase shall not cause a grid disconnect.

[IRIS.StepChange.1.9] The transient resulting from the design-basis step load increase shall not cause any pressurizer safety valves to open.

[IRIS.StepChange.1.10] The transient resulting from the design-basis step load increase shall not cause any steam line safety valves to open.

[IRIS.StepChange.1.11] The transient resulting from the design-basis step load increase shall not cause any steam line relief valves to open.

[IRIS.StepChange.1.12] The transient resulting from the design-basis step load increase shall not cause any turbine bypass valves to open.

[IRIS.StepChange.1.13] The transient resulting from the design-basis step load increase shall not uncover the pressurizer heaters.

[IRIS.StepChange.1.14] The transient resulting from the design-basis step load increase shall not cause high frequency rod stepping.

[IRIS.StepChange.1.15] The transient resulting from the design-basis step load increase shall not cause any neutron flux signals used for automatic control or protection to exceed the value corresponding to $103 \%$ of licensed power.

[IRIS.StepChange.1.16] The transient resulting from the design-basis step load increase shall not cause the parameter used to initiate the transient to overshoot its final setting by more than $30 \%$ of the setting change.

[IRIS.StepChange.1.17] The transient resulting from the design-basis step load increase shall not cause the steam superheat at the turbine inlet to drop below 25 Celsius degrees.

\subsubsection{STEP LOAD DECREASE}

The 10 percent step load decrease transient described here is an artificial transient used for control system performance evaluation, and does not represent a realistic transient for an electric power generating station. In practice, there can only be two ways to initiate such a transient: 
- Have the operator initiate the transient: One would be hard-pressed to suggest a scenario where such a large load change would be required and the precise magnitude and timing known in advance. Expected load changes can invariably be accommodated by slower ramp load changes. Many plants do not allow the operator to request step load changes; instead, they restrict the operator's actions to limit load changes to the design ramp rate.

- Have the plant respond to sudden grid load changes: A grid disturbance outside the plant can separate the plant from the infinite grid, and lead to a change in the generator load. The only mechanism available for detecting sudden grid load changes is the sudden change in grid frequency. By convention, these are classified as islanding events and excluded from the definition of step load changes.

Although step load changes are not realistic transients, designers analyze them for several reasons. First, and most important, they are among the best transients for evaluating control system performance characteristics such as overshoot, damping ratio, and settling time. Second, and of less importance, step load changes generally result in larger excursions from nominal plant conditions than the ramp load changes do, so they are useful indicators of worse-case bounds on the margins to certain reactor trip set points and other plant limits. Normal analysis practice requires that the starting and ending powers lie within the normal maneuvering range and that the initial conditions are nominal conditions with perhaps some deliberate bias for conservatism.

The definition of the design-basis step load decrease is as follows:

- A load change results from an operator request to the supervisory control system.

- The load change request is for an instantaneous decrease in demanded power generation of up to 10 percent of guaranteed electrical output.

- The initial plant electrical output does not exceed $100 \%$.

- The final demanded output is at least 20 percent.

- The step load decrease can occur at any time during the core cycle.

- The plant initial condition is quasi-steady state.

- All relevant process variables begin at their nominal values for the initial plant power.

- All relevant plant systems are operational and remain so.

- All relevant I\&C systems are in automatic control.

The specific requirements defining acceptable responses to step load decreases (from a control and operations perspective) are as follows: 
[IRIS.StepChange.2] The IRIS plant shall be able to perform the design-basis step load decrease.

[IRIS.StepChange.2.1] The transient resulting from the design-basis step load decrease shall bring the plant to a quasi-steady state condition without manual intervention.

[IRIS.StepChange.2.2] The transient resulting from the design-basis step load decrease shall not create diverging oscillations in any plant process variables (i.e. temperatures, pressures, flows, levels, etc.).

[IRIS.StepChange.2.3] The transient resulting from the design-basis step load decrease shall not cause a reactor trip.

[IRIS.StepChange.2.4] The transient resulting from the design-basis step load decrease shall not cause ESF actuation.

[IRIS.StepChange.2.5] The transient resulting from the design-basis step load decrease shall not cause a turbine trip.

[IRIS.StepChange.2.6] The transient resulting from the design-basis step load decrease shall not cause a turbine runback.

[IRIS.StepChange.2.7] The transient resulting from the design-basis step load decrease shall not cause a generator trip.

[IRIS.StepChange.2.8] The transient resulting from the design-basis step load decrease shall not cause a grid disconnect.

[IRIS.StepChange.2.9] The transient resulting from the design-basis step load decrease shall not cause any pressurizer safety valves to open.

[IRIS.StepChange.2.10] The transient resulting from the design-basis step load decrease shall not cause any steam line safety valves to open.

[IRIS.StepChange.2.11] The transient resulting from the design-basis step load decrease shall not cause any steam line relief valves to open.

[IRIS.StepChange.2.12] The transient resulting from the design-basis step load decrease shall not cause any turbine bypass valves to open.

[IRIS.StepChange.2.13] The transient resulting from the design-basis step load decrease shall not uncover the pressurizer heaters.

[IRIS.StepChange.2.14] The transient resulting from the design-basis step load decrease shall not cause high frequency rod stepping.

[IRIS.StepChange.2.15] The transient resulting from the design-basis step load decrease shall not cause any neutron flux signals used for automatic control or protection to exceed the value corresponding to $103 \%$ of licensed power.

[IRIS.StepChange.2.16] The transient resulting from the design-basis step load decrease shall not cause the parameter used to initiate the 
transient to undershoot its final setting by more than $30 \%$ of the setting change.

[IRIS.StepChange.2.17] The transient resulting from the design-basis step load decrease shall not cause the steam superheat at the turbine inlet to drop below 25 Celsius degrees.

\subsubsection{RAMP LOAD INCREASE}

Ramp load changes are the normal method for changing plant generation. Most power plant vendors specify ramp load change capabilities as part of their contractual guarantees. The plant ramp rate limit is generally determined by component limits factors, often either turbine loading limits or component thermal stress limits. In practice, most grids do not require that their nuclear units execute fast ramps over large ranges. The magnitude of the ramp load increase is deliberately left undefined in these requirements because the utility requirement for rapid load changes is defined as a separate event, specifically, the short-term load increase.

The definition of the design-basis ramp load increase is as follows:

- A load change results from an operator request to the supervisory control system.

- The load change request is for a uniform ramp increase in demanded power generation at a rate of up to 5 percent-per-minute of guaranteed electrical output.

- The magnitude of the ramp load increase may be subject to core power distribution limits.

- The magnitude of the ramp load increase may be subject to turbine stress limits.

- The initial plant electrical output is at least $20 \%$ and less than $100 \%$.

- The final demanded electrical output does not exceed $100 \%$.

- The ramp load increase can occur at any time during the core cycle.

- The plant initial condition is quasi-steady state.

- All relevant process variables begin at their nominal values for the initial plant power.

- All relevant plant systems are operational and remain so.

- All relevant I\&C systems are in automatic control.

- The initial control rod position provides for adequate rod withdrawal during the resulting transient.

The specific requirements defining acceptable responses to ramp load increases (from a control and operations perspective) are as follows: 
[IRIS.RampChange.1] The IRIS plant shall be able to perform the design-basis ramp load increase.

[IRIS.RampChange.1.1] The transient resulting from the design-basis ramp load increase shall bring the plant to a quasi-steady state condition without manual intervention.

[IRIS.RampChange.1.2] The transient resulting from the design-basis ramp load increase shall not create diverging oscillations in any plant process variables (i.e. temperatures, pressures, flows, levels, etc.).

[IRIS.RampChange.1.3] The transient resulting from the design-basis ramp load increase shall not cause a reactor trip.

[IRIS.RampChange.1.4] The transient resulting from the design-basis ramp load increase shall not cause ESF actuation.

[IRIS.RampChange.1.5] The transient resulting from the design-basis ramp load increase shall not cause a turbine trip.

[IRIS.RampChange.1.6] The transient resulting from the design-basis ramp load increase shall not cause a turbine runback.

[IRIS.RampChange.1.7] The transient resulting from the design-basis ramp load increase shall not cause a generator trip.

[IRIS.RampChange.1.8] The transient resulting from the design-basis ramp load increase shall not cause a grid disconnect.

[IRIS.RampChange.1.9] The transient resulting from the design-basis ramp load increase shall not cause any pressurizer safety valves to open.

[IRIS.RampChange.1.10] The transient resulting from the design-basis ramp load increase shall not cause any steam line safety valves to open.

[IRIS.RampChange.1.11] The transient resulting from the design-basis ramp load increase shall not cause any steam line relief valves to open.

[IRIS.RampChange.1.12] The transient resulting from the design-basis ramp load increase shall not cause any turbine bypass valves to open.

[IRIS.RampChange.1.13] The transient resulting from the design-basis ramp load increase shall not uncover the pressurizer heaters.

[IRIS.RampChange.1.14] The transient resulting from the design-basis ramp load increase shall not cause high frequency rod stepping.

[IRIS.RampChange.1.15] The transient resulting from the design-basis ramp load increase shall not cause any neutron flux signals used for automatic control or protection to exceed the value corresponding to $103 \%$ of licensed power.

[IRIS.RampChange.1.16] The transient resulting from the design-basis ramp load increase shall not cause the parameter used to initiate the 
transient to overshoot its final setting by more than $30 \%$ of the setting change required to initiate a $10 \%$ step.

[IRIS.RampChange.1.17] The transient resulting from the design-basis ramp load increase shall not cause the steam superheat at the turbine inlet to drop below 25 Celsius degrees.

\subsubsection{RAMP LOAD DECREASE}

Ramp load changes are the normal method for changing plant generation. Most power plant vendors specify ramp load change capabilities as part of their contractual guarantees. The plant ramp rate limit is generally determined by component limits factors, often either turbine loading limits or component thermal stress limits. In practice, most grids do not require that their nuclear units execute fast ramps over large ranges. The magnitude of the ramp load decrease is deliberately left undefined in these requirements because the utility requirement for rapid load changes is defined as a separate event, specifically, the short-term load decrease.

The definition of the design-basis ramp load decrease is as follows:

- A load change results from an operator request to the supervisory control system.

- The load change request is for a uniform ramp decrease in demanded power generation at a rate of up to -5 percent-per-minute of guaranteed electrical output.

- The initial plant electrical output is greater than $20 \%$ and no more than $100 \%$

- The final demanded plant electrical output is no less than $20 \%$

- The ramp load decrease can occur at any time during the core cycle.

- The magnitude of the ramp load decrease may be subject to core power distribution limits.

- The magnitude of the ramp load decrease may be subject to turbine stress limits.

- The plant initial condition is quasi-steady state.

- All relevant process variables begin at their nominal values for the initial plant power.

- All relevant plant systems are operational and remain so.

- All relevant I\&C systems are in automatic control.

The specific requirements defining acceptable responses to ramp load decreases (from a control and operations perspective) are as follows: 
[IRIS.RampChange.2] The IRIS plant shall be able to perform the design-basis ramp load decrease.

[IRIS.RampChange.2.1] The transient resulting from the design-basis ramp load decrease shall bring the plant to a quasi-steady state condition without manual intervention.

[IRIS.RampChange.2.2] The transient resulting from the design-basis ramp load decrease shall not create diverging oscillations in any plant process variables (i.e. temperatures, pressures, flows, levels, etc.).

[IRIS.RampChange.2.3] The transient resulting from the design-basis ramp load decrease shall not cause a reactor trip.

[IRIS.RampChange.2.4] The transient resulting from the design-basis ramp load decrease shall not cause ESF actuation.

[IRIS.RampChange.2.5] The transient resulting from the design-basis ramp load decrease shall not cause a turbine trip.

[IRIS.RampChange.2.6] The transient resulting from the design-basis ramp load decrease shall not cause a turbine runback.

[IRIS.RampChange.2.7] The transient resulting from the design-basis ramp load decrease shall not cause a generator trip.

[IRIS.RampChange.2.8] The transient resulting from the design-basis ramp load decrease shall not cause a grid disconnect.

[IRIS.RampChange.2.9] The transient resulting from the design-basis ramp load decrease shall not cause any pressurizer safety valves to open.

[IRIS.RampChange.2.10] The transient resulting from the design-basis ramp load decrease shall not cause any steam line safety valves to open.

[IRIS.RampChange.2.11] The transient resulting from the design-basis ramp load decrease shall not cause any steam line relief valves to open.

[IRIS.RampChange.2.12] The transient resulting from the design-basis ramp load decrease shall not cause any turbine bypass valves to open.

[IRIS.RampChange.2.13] The transient resulting from the design-basis ramp load decrease shall not uncover the pressurizer heaters.

[IRIS.RampChange.2.14] The transient resulting from the design-basis ramp load decrease shall not cause high frequency rod stepping.

[IRIS.RampChange.2.15] The transient resulting from the design-basis ramp load decrease shall not cause any neutron flux signals used for automatic control or protection to exceed the value corresponding to $103 \%$ of licensed power.

[IRIS.RampChange.2.16] The transient resulting from the design-basis ramp load decrease shall not cause the parameter used to initiate the 
transient to undershoot its final setting by more than $30 \%$ of the setting change of the setting change required to initiate a $-10 \%$ step.

[IRIS.RampChange.2.17] The transient resulting from the design-basis ramp load decrease shall not cause the steam superheat at the turbine inlet to drop below 25 Celsius degrees. 


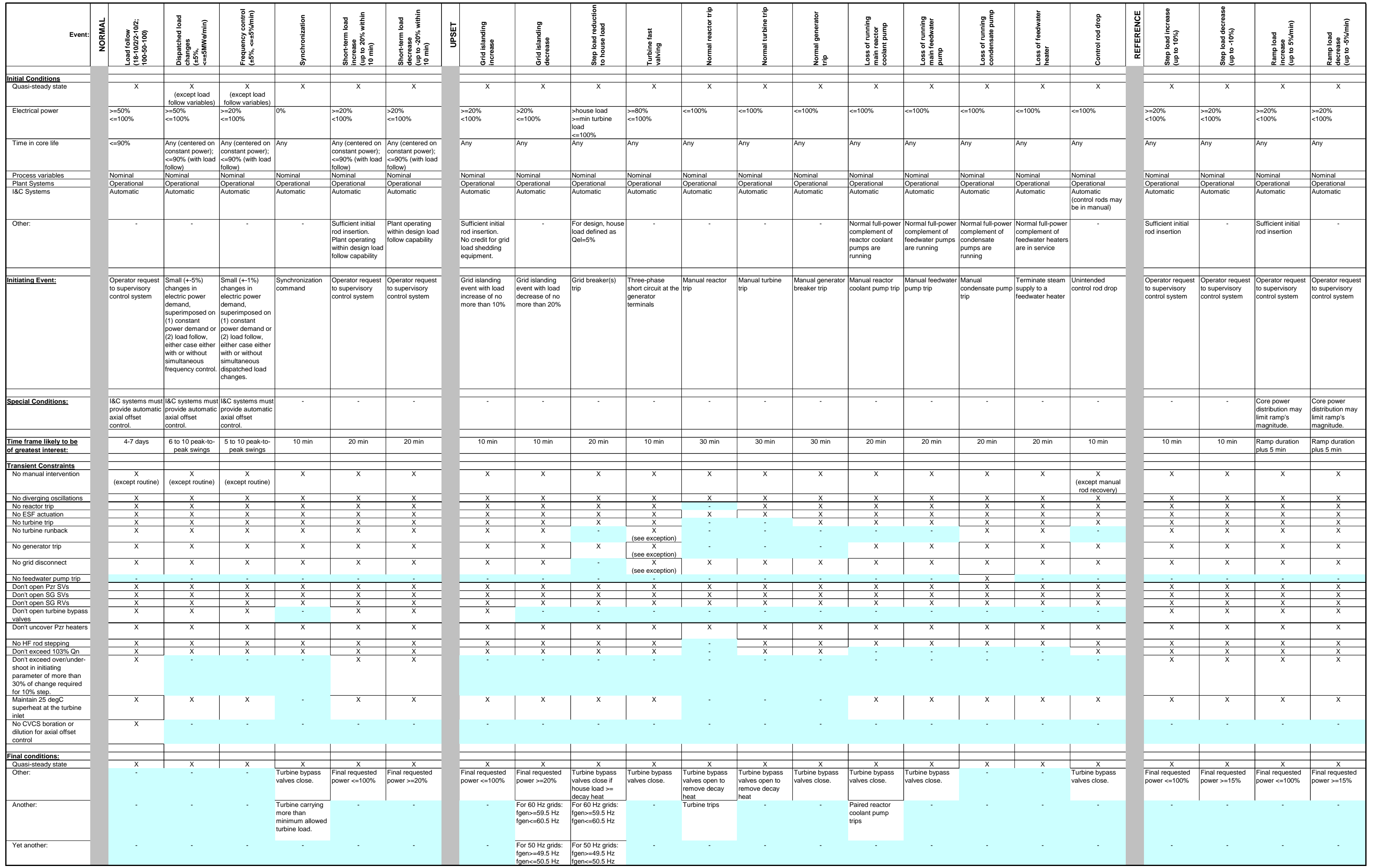

Figure 1: Summary of Maneuverability Requirements 


\section{SUMMARY}

The current vision for IPSR deployment includes multi-unit sites and the possibility of coupling the plant with co-generation modules such as desalination, district heating, and industrial steam. Earlier work outlined concepts for controlling single units for electric power generation. The present study is investigating supervisory control of all units at a single site with the twin (and possibly competing) objectives of simplifying operation and/or optimizing the operational economics of the site suite, especially when the site objectives augment electric power generation with desalination or other goals.

We continue to look at the plant maneuvering requirements proposed in 2004 . When necessary, we modify them to account for new operational considerations and knowledge gained during the design process. We continue to refine the lowlevel and unit control strategies, and continue to investigate concepts for multiunit control. One promising approach is to tailor standard economic dispatch algorithms to fit the single-site, multi-unit environment. These algorithms perform a constrained economic optimization to determine each units preferred output on a minute-by-minute basis. In the 1980s, Westinghouse developed concepts to update the constraints used in the optimization continuously. We envision using similar techniques for IRIS. At the same time, advanced control concepts may allow one to relax some of the traditional constraints. One example is automated axial power distribution control using multiple control rod groups, which eliminates load follow constraints imposed by boron dilution limits. The second is dynamic deadbands for short-term load changes, which allow larger fluctuations while limiting key component wear, particularly associated with the control rod drives.

We reviewed the impact of using turbine extraction steam for desalination and district heating. The options currently preferred would require perhaps 5 percent of the NSSS thermal output and result in an electric power output reduction of roughly half that percentage. By comparison, the Temelin plant supports district heating of up to roughly 11 percent of rated thermal power. Temelin manages to control district heating through balance-of-plant controls only, without any interface with the unit's Control Coordinator or NSSS controls. By analogy, we expect that using turbine extraction steam for desalination or district heating would demand little or no special consideration by the IRIS Supervisory or NSSS controls.

Multi-unit control would provide the greatest benefit if there were one operating staff charged with controlling all modules on a site. This is common practice in some industries, but not in commercial nuclear power. The key is to limit staff workload by providing a high level of unit and site automation. We will review the human factors implications separately as part of the Task 5 effort. 


\section{REFERENCES}

1. Holcomb, D. E. (Oak Ridge National Laboratory, USA) and A. C. Barroso (Instituto de Pesquisas Energéticas e Nuclearares, BRAZIL) Collaborative Proposal for the International Nuclear Energy Research Initiative, "Development of Advanced Instrumentation and Control for an Integrated Primary System Reactor,” December 15, 2004.

2. Storrick, G. D. and F. Schiavo, STD-ES-04-34, "IRIS Control Systems Conceptual Design," Sep. 2004.

3. Lipner, M. H., R. A. Dudics, J. W. Willis and R. A. Mundy, "Supervisory Sequential Controller Interface system," 2000 ANS/ENS International Meeting, Washington, D.C., November 12-16, 2000.

4. Ingersoll, D. T., L. L. Binder, D. Conti, and M. E. Ricotti, "Nuclear desalination options for the International Reactor Innovative and Secure (IRIS)," $5^{\text {th }}$ International conference on nuclear option in countries with small and medium electricity grids, Bubrovnik, Croatia, May 16-20, 2004.

5. Kostin, V. I., Yu. K. Panov, V, I. Polunichev, S. A. Fateev, and L. V. Gureeva, "Nuclear power desalination complex with IRIS reactor plant and Russian distillation desalinating unit," $5^{\text {th }}$ International conference on nuclear option in countries with small and medium electricity grids, Bubrovnik, Croatia, May 16-20, 2004.

6. Wood, Allen J. and Bruce F. Wollenberg, "Power generation, operation, and control," Wiley-Interscience, 1996, ISBN 0471586994. 